\title{
Mesenchymal Stem Cell Therapy Ameliorates Metabolic Dysfunction and Restores Fertility in a PCOS Mouse Model Through Interleukin-10
}

\section{Rishi Man Chugh}

University of Illinois at Chicago

Hang-soo Park

The University of Chicago https://orcid.org/0000-0002-9130-8478

Abdeljabar El Andaloussi

University of Illinois at Chicago

Amro Elsharoud

University of Illinois at Chicago

\section{Sahar Esfandyari}

University of Illinois at Chicago

\section{Mara Ulin}

University of Illinois at Chicago

\section{Lale Bakir}

University of Illinois at Chicago

\section{Alshimaa Aboalsoud}

University of Illinois at Chicago

\section{Mohamed Ali}

University of Illinois at Chicago

\section{Dalia Ashour}

University of Illinois at Chicago

\section{Prosper Igboeli}

University of Illinois at Chicago

\section{Nahed Ismail}

University of Illinois at Chicago

\section{Jan McAllister}

Penn State College of Medicine

Ayman Al-Hendy ( $\nabla$ aalhendy@bsd.uchicago.edu )

Department of Surgery, University of Illinois at Chicago, 820 South Wood Street, Chicago, IL 60612, USA https://orcid.org/0000-0002-6512-603X 
Keywords: Mesenchymal stem cells (MSCs), Cell transplantation, Cytokines, Interleukin

Posted Date: April 23rd, 2021

DOI: https://doi.org/10.21203/rs.3.rs-444566/v1

License: (c) (1) This work is licensed under a Creative Commons Attribution 4.0 International License. Read Full License

Version of Record: A version of this preprint was published at Stem Cell Research \& Therapy on July 7th, 2021. See the published version at https://doi.org/10.1186/s13287-021-02472-w. 


\section{Abstract}

Background: Polycystic ovary syndrome (PCOS) is the most common endocrine and metabolic disorder in reproductive-age women. Excessive inflammation and elevated androgen production from ovarian theca cells are key features of PCOS. Human bone marrow mesenchymal stem cells (BM-hMSC) and their secreted factors (secretome) exhibit robust anti-inflammatory capabilities in various biological systems. We evaluated the therapeutic efficacy of BM-hMSC and its secretome in both in vitro and in vivo PCOS models.

Methods: For in vitro experiment, we treated conditioned media from BM-hMSC to androgen producing H293R cells, and analyzed androgen producing gene expression. For in vivo experiment, BM-hMSC were implanted into Letrozole (LTZ) induced mouse PCOS model. BM-hMSC effect in androgen producing cells or PCOS model mice was assessed by monitoring cell proliferation (immunohistochemistry), steroidogenic gene expression (quantitative real-time polymerase chain reaction [qRT-PCR] and Western blot, animal tissue assay (H\&E staining), and fertility by pup delivery.

Results: BM-hMSC significantly downregulate steroidogenic gene expression, curb inflammation, and restore fertility in treated PCOS animals. The anti-inflammatory cytokine interleukin-10 (IL-10) played a key role in mediating the effects of BM-hMSC in our PCOS models. We demonstrated that BM-hMSC treatment was improve in metabolic and reproductive markers in our PCOS model and able to restore fertility.

Conclusion: Our study demonstrates for the first time the efficacy of intra-ovarian injection of BM-hMSC or its secretome to treat PCOS-related phenotypes, including both metabolic and reproductive dysfunction. This approach may represent a novel therapeutic option for women with PCOS. Our results suggest that BM-hMSC can reverse PCOS-induced inflammation through IL-10 secretion. BM-hMSC might be a novel and robust therapeutic approach for PCOS treatment.

\section{Background}

Polycystic ovary syndrome (PCOS) is the most common endocrine disorder affecting $15-18 \%$ of reproductive-age women $(1,2)$. The disorder is characterized by hyperandrogenism, ovulatory dysfunction, and polycystic ovarian morphology (1). Ovulatory dysfunction can lead to infertility and endometrial cancer $(3,4)$. Many women with PCOS also exhibit metabolic aberrations such as insulin resistance, dyslipidemia, and hypertension, which are often worsened by concomitant abdominal adiposity or frank obesity. These factors can predispose women to abnormal glucose tolerance, cardiovascular disease, and even full-blown metabolic syndrome (5-7).

Women with PCOS exhibit chronic low-grade inflammation that can be perpetuated by ingestion of nutrients $(8,9)$. In PCOS, molecular markers of inflammation triggered by glucose and saturated fat are highly correlated with insulin resistance and hyperandrogenemia (8-11). Chronic androgen suppression does not decrease inflammation in PCOS (12), and pro-inflammatory stimuli are capable of increasing 
theca cell androgen production and the expression of enzymes responsible for producing androgens in vitro (13). Recently, anti-inflammatory therapy has been shown to reduce ovarian androgen secretion and induce ovulation in lean, insulin-sensitive women with PCOS (14). These findings clearly implicate inflammation as an underlying mechanism of ovarian dysfunction even in the absence of insulin resistance in PCOS.

In the last decade, extensive research has focused on the immunosuppressive and anti-inflammatory effects of bone marrow mesenchymal stem cells (BM-hMSC). Several reports suggest that these effects are mediated by secreted factors including interleukin (IL)-10, an anti-inflammatory cytokine (14-16). These secreted factors are either released following cross-talk with target cells or produced constitutively by BM-hMSC $(15,17)$. As chronic low-grade inflammation is strongly implicated as a driver of pathophysiology in PCOS(18), we hypothesized that interventions involving BM-hMSC or its secreted factors can improve the endocrine and metabolic abnormalities observed in PCOS, as well as fertility outcomes.

Mice receiving letrozole (LTZ), a nonsteroidal aromatase inhibitor, exhibit increases in circulating testosterone due to impaired conversion of testosterone to estrogen (19). These mice exhibit the hallmarks of hyperandrogenism, anovulation, and polycystic ovaries, as well as impaired fertility and the metabolic dysregulation often observed in women with PCOS $(19,20)$. Recently, anti-inflammatory therapy has been shown to reverse key features of the PCOS phenotype in this mouse model (11). Thus, the LTZ-induced PCOS mouse is a useful model to evaluate the effect of BM-hMSC on inflammatory pathophysiological mechanisms in PCOS, and to establish novel stem cell-based therapeutics for PCOS. Because approximately half of women diagnosed with PCOS have excessive adrenal androgen production (21-23), androgen-producing human adrenocortical-carcinoma cells (H295R) represent a good in vitro model of PCOS.

We analyzed the effects of exposing H295R cells to the BM-hMSC secretome and IL-10 on testosterone production and the expression of genes encoding enzymes involved in androgen biosynthesis. We performed similar experiments on primary cultures of theca cells obtained from women with PCOS. Finally, we examined the effect of intra-ovarian injection of BM-hMSC on inflammation, metabolism, and ovarian and endometrial gene expression, as well as measures of fertility, in LTZ-induced PCOS mice.

\section{Methods}

\section{Human bone-marrow mesenchymal stem cell culture}

Human BM-hMSC (Passage 2) were purchased from Lonza, USA (PT\#2501). These cells were isolated from the bone marrow of a healthy non-diabetic female donor 32-year-old. The cells were cultured in mesenchymal stem cell growth medium (MSCGM) per the manufacturer's recommended expansion protocol. When the culture reached approximately $80 \%$ confluence, cells were trypsinized using a $0.05 \%$ trypsin-EDTA solution and serially expanded for use in experiments. Cells were characterized for typical 
BM-MSC-positive (CD90, CD73, CD105) and negative (CD34, CD11b, CD19, CD45, HLA-DR) cell surface markers using the human MSC analysis kit (BD Stemflow ${ }^{\mathrm{TM}}$, CA, USA cat. no. 562245).

\section{Human adrenocortical-carcinoma cell line culture}

Human adrenocortical-carcinoma cells (H295R cells) were used as an in vitro cell culture model for androgen production. These cells are commonly used in studies of steroidogenesis and androgen biosynthesis pathways (21-23). H295R cells were purchased from ATCC (Manassas, VA, USA, cat. no. ATCC ${ }^{\circledR}$ CRL-2128 ${ }^{\text {TM }}$ ) and cultured per the recommended guidelines. Briefly, H295R cells were cultured in flasks pre-coated with extracellular matrix (Gibco, USA, cat. no. S-006-100) with DMEM/F12 (Gibco, cat. no. 21041025 ) and $2.5 \%$ Nu-Serum (Corning, USA). The cells were subcultured at a ratio of $1: 3$ to $1: 4$ and culture media were changed twice a week.

\section{Human theca cell culture from women with PCOS}

Human theca interna tissue was collected at the time of oophorectomy $(n=2)$, which was performed as clinically indicated using a protocol (24-27) approved by the Institutional Review Board of The Pennsylvania State University College of Medicine. Theca cells from PCOS ovarian follicles were isolated and cultured as previously reported $(28,29)$. The follicles were isolated from the ovaries and dissected under a microscope in a dish containing a 1:1 mixture of DMEM and Ham's F12 medium supplemented with $10 \%$ fetal bovine serum (FBS). The cleaned theca shells were digested with $0.05 \%$ collagenase I, $0.05 \%$ collagenase IA, and $0.01 \%$ deoxyribonucleic, in medium containing $10 \% \mathrm{FBS}$. The isolated cells were cultured in dishes pre-coated with fibronectin in a 1:1 mixture of DMEM and Ham's F12 medium containing 10\% FBS, 10\% horse serum, 2\% UltroSer G, $20 \mathrm{~nm}$ insulin, $20 \mathrm{~nm}$ selenium, $1 \mu \mathrm{M}$ vitamin $\mathrm{E}$, and antibiotics. Experiments were performed using passage 4 (31-38 population doublings) PCOS theca cells.

\section{Preparation of the BM-hMSC secretome}

The secretome was prepared from three to five passages of BM-hMSC in T75 flasks. Media were collected and discarded from the BM-hMSC culture at $80-90 \%$ confluence. Cells were then washed three times with phosphate-buffered saline (PBS) for complete removal of serum. Cells were then maintained in DMEM/F12 (Gibco, USA) serum-free media for 24 hours to collect the secretome. After 24 hours, the media were collected, centrifuged at $500 \mathrm{~g}$ for $5 \mathrm{~min}$ at $4^{\circ} \mathrm{C}$ to remove the cell debris, aliquoted, and stored at $-80^{\circ} \mathrm{C}$ for use in experiments. DMEM/F12 serum-free media without cells were incubated for 24 hours in the T75 cell culture flask to serve as a negative control.

For in vivo experiments, the secretome was collected using the above method, and cultured cells were trypsinized from the flasks and counted. The average cell count was $2.25 \times 10^{6}$ cells per flask. The collected BM-hMSC media were then aliquoted at a volume calculated based on the cell secretions from 5 $X 10^{5}$ cells on average per ovary of each mouse. The media/secretome were concentrated using a vacuum concentrator (Labconco, MO, USA) and stored at $-80^{\circ} \mathrm{C}$ for use in in vivo experiments. Before 
intra-ovarian injection, the concentrated secretome was reconstituted with PBS to a final volume of $10 \mu \mathrm{l}$ per ovary.

\section{Treatment of H295R cells and human PCOS theca cells with the BM-hMSC secretome}

H295R cells and human PCOS theca cells were cultured separately on pre-coated six-well plates for 48 hours. Cells were then treated for 24 hours with secretome diluted in basal media (serum-free) at a 1:1 ratio. Cell culture media were replaced with serum-free media or secretome media, and cells were incubated for an additional 24 hours. After the incubation period, cells were collected for analysis of steroidogenesis-related gene expression. Cell culture media was used for hormone quantification using an automated chemiluminescence immunoassay system, UniCel Dxl 800, Access Immunoassay System (Beckman Coulter Inc., CA, USA) (30).

\section{Treatment of H295R cells with recombinant human IL-10}

To investigate the anti-inflammatory effect of the BM-hMSC secretome, we measured the amount of IL-10 secreted by BM-hMSC into the culture media by ELISA (Abcam, Cambridge, MA, USA) following the manufacturer's instructions (17). We explored the effect of IL-10 on steroidogenesis-related gene expression, androgen secretion, and pro-inflammatory marker expression in H295R cells after treatment with $0,125,250$, or $500 \mathrm{pg} / \mathrm{ml}$ recombinant human IL-10 (rhIL-10; R \& D Biosystem, Cat No. 217-IL-010). These concentrations were selected based on the previously reported level of IL-10 secreted by hMSCs (31). H295R cells were then collected for gene expression analysis, and cell culture media were used for measurement of testosterone using an automated chemiluminescence immunoassay system, UniCel DxI 800, Access Immunoassay System (Beckman Coulter Inc., CA, USA) (30) and androstenedione using ELISA (Biovision, CA, USA) (32).

\section{PCOS mouse model and intra-ovarian injection of BM-hMSC}

Three-week-old female C57BL/6 mice (Charles River, MA, USA) were housed in a vivarium for 1 week under specific pathogen-free conditions. The animal experiment protocol for this study was approved by the University of Illinois at Chicago Animal Care Committee (UIC ACC). All animal experiments were performed in compliance with the University of Illinois at Chicago's policies and guidelines for use of laboratory animals.

At 4 weeks of age, mice ( $n=10 /$ group) were subcutaneously implanted with a placebo or $5 \mathrm{mg}$ LTZ pellet (Innovative Research of America, Sarasota, FL, USA), which provides a constant release of LTZ (50 $\mu \mathrm{g} /$ day). Body weight was monitored weekly before and post-implantation. Body weight and insulin resistance (measured by glucose tolerance test, GTT) were used to monitor development of PCOS characteristics.

Five weeks after placebo or LTZ pellet implantation, mice underwent intra-ovarian injection of BM-hMSC via laparotomy. Mice were treated preoperatively with a single dose of buprenorphine $(0.1 \mathrm{mg} / \mathrm{kg})$ and were kept under anesthesia with $1-4 \%$ inhalation of isoflurane during the entire procedure. A single 
midline incision, less than $25 \mathrm{~mm}$, was made on the skin to access both ovaries via the caudal abdominal cavity. For the BM-hMSC group, cells were injected in both ovaries at a concentration of $5.0 \times 10^{5}$ cells per ovary resuspended in $10 \mu \mathrm{l}$ PBS. For the secretome group, concentrated secretome reconstituted in 10 $\mu \mathrm{L}$ PBS was injected per ovary in both ovaries. For the control group, $10 \mu \mathrm{l}$ of PBS was injected into both ovaries. The incision was closed by suturing, followed by wiping with a clean disinfectant swab. Two weeks after BM-hMSC engraftment or secretome injection, the mice were anesthetized and gonadal fat pads, brown fat, and ovaries were collected. A portion of the gonadal and brown fat, as well as one ovary, were fixed in $4 \%$ paraformaldehyde and embedded in paraffin; the remainder of the tissue and the other ovary was frozen at $-80^{\circ} \mathrm{C}$ for further analysis.

\section{Glucose tolerance test}

Glucose tolerance testing was performed on mice 5 weeks after placebo or LTZ pellet implantation and 2 weeks after BM-hMSC engraftment or secretome treatment. Mice were fasted for 16 h ( 5 p.m. to 9 a.m.), with free access to drinking water, after which they received an intraperitoneal (i.p.) injection of D-glucose ( $2.0 \mathrm{~g} / \mathrm{kg}$ body weight). Blood glucose level was measured at $0,15,30,60,90$, and 120 min following glucose injection using a Bayer glucose monitor (Roche Diagnostics Corp, IN, USA).

\section{Indirect calorimetry}

Metabolic rate was measured in mice at 11 weeks of age by indirect calorimetry in open-circuit Oxymax chambers, a unit of the Comprehensive Lab Animal Monitoring System (CLAMS; Columbus Instruments, state, USA). Two weeks after BM-hMSC treatment, mice receiving LTZ only or LTZ and treated with BMhMSC $(n=3)$ were acclimated to calorimetry cages for 2 days before data sampling at $23^{\circ} \mathrm{C}$ under $12: 12$ hours light:dark cycle. Oxygen consumption rate $\left(\mathrm{VO}_{2}\right)$, carbon dioxide release $\left(\mathrm{VCO}_{2}\right)$, respiratory exchange ratio (RER), and heat production were measured in individual mice. The horizontal activity was measured on $x, y$, and z-axes.

\section{Serum hormone measurements}

Blood was collected from all the groups by cardiac exsanguination under isoflurane anesthesia; serum was separated and stored at $-80^{\circ} \mathrm{C}$. Serum hormone levels were measured at the University of Virginia Ligand Core Facility. Serum testosterone (T) and estradiol (E2) levels were measured using ELISA. Serum luteinizing hormone (LH) and follicle-stimulating hormone (FSH) levels were measured by radioimmunoassay (RIA). The sensitivities of each assay are $10 \mathrm{ng} / \mathrm{dL}(\mathrm{T}), 3 \mathrm{pg} / \mathrm{ml}(\mathrm{E} 2), 3 \mathrm{ng} / \mathrm{ml}(\mathrm{FSH})$, and $0.04 \mathrm{ng} / \mathrm{ml}(\mathrm{LH})$. Serum cytokines were analyzed in a membrane-based antibody array (Ray Biotech, GA, USA) per the manufacturer's protocol.

\section{Breeding experiments}

One week after BM-hMSC engraftment or secretome treatment, 6 mice per group were randomly selected for the breeding experiment. One male C57BL/ 6 breeder mouse was used for every two female mice. The 
male and female mice were caged together for 10 days. Mating was determined by the presence of sperm plug in the vagina. Most of the female mice showed a sperm plug within 3 days, and the average number of pups from each female mouse was compared between treatment groups. At the end of the experiment, all delivered pups were counted per group, their body weight was measured, and any morphological anomalies were noted.

\section{Histology and immunohistochemistry}

Ovaries and fat tissues were collected, fixed in 4\% paraformaldehyde, and embedded in paraffin blocks. Tissue sections were stained with hematoxylin-eosin (H\&E) and murine anti-UCP-1 (Abcam, MA, USA), followed by detection with a biotin-labeled rabbit anti-rat antibody and staining with the $A B C$ kit (Vector Laboratories, Burlingame, CA, USA). Sample processing and staining were performed the histology core of the University of Illinois at Chicago (Chicago, IL, USA). Histological analyses were performed using Asperio ImageScope (Leica Biosystem, Wetzlar, Germany).

\section{Immunoblot analysis}

Following treatment of H295R cells and human PCOS theca cells with the BM-hMSC secretome, and treatment of mice with BM-hMSC or its secretome, cultured cells and collected ovarian tissue were lysed with RIPA buffer (Cell Signaling, MA, USA) containing protease and phosphatase inhibitor cocktail (Thermo Fisher Scientific Inc., MA, USA) and sonicated at 20 amplitude with $5 \mathrm{sec}$ on and $5 \mathrm{sec}$ off for a 1-minute cycle. Sonicated samples were then centrifuged at 12,000 rpm for $5 \mathrm{~min}$ and the supernatant was transferred into separate tubes. The protein concentration of all samples was determined by the Bradford method. For immunoblot analysis, samples containing equal amounts of protein were incubated with $1 x$ gel loading buffer and separated by SDS-PAGE (4-20\% criterion, Bio-Rad), then transferred to PVDF membrane using a Trans-blot turbo system (Bio-Rad, Hercules, CA, USA). After protein transfer, blocked membranes were incubated in $1 \%$ non-fat dry milk in $1 \times$ PBS $(0.05 \%$ Tween) overnight at $4^{\circ} \mathrm{C}$, with primary antibodies against CYP17A1 (ab125022, 1:500 dilution, Abcam), CYP11A1 (ab75497, 1:500 dilution, Abcam), DENND1A (LS-C167356, 1:250, LSBio), VEGFA (ab1316, 1:500 dilution, Abcam), or $\beta$-actin (clone AC-15, A5441, 1:5000, Sigma) in 1\% non-fat dry milk in 1x PBS with $0.05 \%$ Tween overnight at $4^{\circ} \mathrm{C}$. After washing, the membrane was incubated with the appropriate HRP-linked secondary antibodies (anti-mouse secondary antibody, cat. no. 7076, 1:5000 or anti-rabbit secondary antibody, cat. no. 7074, 1:3000, Cell Signaling) in 5\% non-fat dry milk in $1 \times$ PBS with $0.1 \%$ Tween at room temperature for 1 hour. The membrane was developed with Trident Femto Western HRP substrate (GeneTex, Irvine, CA, USA) and visualized using the ChemiDoc XRS + molecular imager (Bio-Rad, Hercules, $\mathrm{CA}$, USA). After imaging, membranes were stripped with Restore ${ }^{\mathrm{TM}}$ PLUS stripping buffer (Thermo Scientific, MA, USA) to incubate with another antibody. The signal density of each protein band was quantified using Image $J$ software (US National Institute of Health, Bethesda, MD, USA) and normalized against the corresponding $\beta$-actin band.

\section{Quantitative RT-PCR}


RNA was extracted from H295R cells and human PCOS theca cells treated with the BM-hMSC secretome or rhIL-10. RNA was also extracted from fat and ovarian tissues collected from mice treated with BMhMSCs or the BM-hMSC secretome. RNA extraction was done using TRIzol (Invitrogen, USA) according to the manufacturer's instructions. The concentration and purity of the extracted RNA were checked using a NanoDrop spectrometer (Thermo Scientific, MA, USA). $1 \mu \mathrm{g}$ of total RNA was reverse transcribed using RNA to cDNA EcoDry ${ }^{\mathrm{TM}}$ Premix (Double Primed) (Takara Bio USA Inc., CA, USA). The reaction mixture was incubated for $1 \mathrm{~h}$ at $42^{\circ} \mathrm{C}$; incubation was stopped at $70^{\circ} \mathrm{C}$ for $10 \mathrm{~min}$. Quantitative real-time PCR (qPCR) was performed using the CFX96 PCR instrument and SYBR Green Supermix (Bio-Rad, Hercules, CA, USA) with specific primers to the target genes in a $20 \mu \mathrm{L}$ final reaction volume. The primer sequences are listed in Table S1. Beta-actin was used as a reference gene for sample normalization. The delta-delta threshold cycle $(\Delta \Delta C \mathrm{t})$ method was used to calculate the fold change expression in mRNA level in the samples.

\section{Flow cytometry (FACS) analysis}

After treatment with the BM-hMSC secretome or basal media control, H295R cells were analyzed by FACS for proliferation, apoptosis, and inflammatory markers using antibodies against Ki67 antibody (BioLegend, Cat no. 350514), Annexin-V (BioLegend, Cat no. 640919), IL-1 $\beta$ (R\&D Systems, Cat no. IC8406A), and TNF-a (BioLegend, Cat no. 502943). In brief, treated cell pellets were harvested and fixed/permeabilized with BD cytofix/cytoperm kit reagent (BD Bioscience, CA, USA) for intracellular staining, per the manufacturer's instructions. After centrifugation at $1500 \mathrm{rpm}$ for 5 minutes, a total of $1 \mathrm{X}$ $10^{6}$ cells were resuspended in $200 \mu \mathrm{l}$ of antibody solution and incubated for $30 \mathrm{~min}$ at room temperature in the dark. After washing, the cells were resuspended in PBS with $2 \%$ FBS (v/v) for FACS analysis using (BD, Gallios, Flow-cytometer). Data were analyzed using FlowJo software.

\section{Statistical analysis}

Comparisons between groups were made by one-way ANOVA with Tukey's post hoc test or Student's ttests. All data are presented as mean \pm standard deviation (SD). A difference between groups with ${ }^{*} p<0.05, * * p<0.005$, or $* * * p<0.0005$ was considered statistically significant.

\section{Results}

\section{BM-hMSC secretome elicits anti-proliferative and apoptotic effects in H295R cells}

H295R cells were incubated with BM-hMSC secretome to evaluate therapeutic potential. After 24 hours, we observed a significant reduction $(7.96 \% \pm 0.23)$ in cell growth rate, as measured by Ki- 67 protein expression compared with control media-treated cells (12.37\% \pm 0.19 ; Fig. 1a). Additionally, secretome treatment significantly increased both early apoptosis $(74.38 \% \pm 1.00$; Fig. $1 \mathrm{~b})$ as well as late apoptosis and necrosis ( $2.43 \% \pm 0.21$; Fig. $1 \mathrm{C})$, as measured by Annexin-V and Annexin-V/7-AAD expression, respectively, compared with the control group $(64.94 \% \pm 1.47$ and $1.30 \% \pm 0.43)$. Thus, our results indicate that BM-hMSC secretome inhibits growth of H295R cells. 


\section{BM-hMSC secretome decreases steroidogenesis-related gene expression and androgen production in H295R cells}

We previously reported that CYP17A1, CYP11A1, and DENND1A, key genes for ovarian androgen biosynthesis, are upregulated in PCOS-theca cells compared with healthy theca cells $(27,33)$. Hence, we evaluated the effect of the BM-hMSC secretome on the expression of these genes using our in vitro model. Secretome treatment resulted in significant downregulation of CYP17A1 ( $0.56 \pm 0.02$ fold) and DENND1A ( $0.37 \pm 0.05$ fold) gene expression in H295R cells compared with media-treated cells (Fig. $1 \mathrm{~d}-\mathrm{f})$. However there was no significant decrease in CYP11A1 gene expression ( $0.82 \pm 0.05$ fold, $p=0.127)$. We confirmed these findings at the protein level using immunoblot analysis, which showed that CYP17A1 $(0.84 \pm 0.02$ fold $)$ and DENND1A ( $0.26 \pm 0.01$ fold $)$ were significantly decreased in secretome-treated H295R cells compared with the control group, while no change was observed in CYP11A1 $(0.97 \pm 0.02$ fold, $p=0.29$; Fig. $1 \mathrm{~g}-\mathrm{i})$. We validated these observations in PCOS patient-derived theca cells $(\mathrm{n}=2)$ treated with BM-hMSC secretome. Secretome treatment significantly downregulated CYP17A1 (Patient 1: $0.36 \pm$ 0.20 fold, Patient 2: $0.05 \pm 0.04$ fold) gene expression (Fig. 1j) and protein expression ( $0.40 \pm 0.39$ fold; Fig. 1k) in theca cells from both patients compared with media-treated controls.

We investigated the effects of steroidogenesis-related gene inhibition by the BM-hMSC secretome on testosterone secretion.We explored whether steroidogenesis-related gene inhibition by the BM-hMSC secretome affected testosterone secretion. Compared with the media control group (474.6 $\pm 27.5 \mathrm{ng} / \mathrm{dL})$, secretome treatment suppressed testosterone secretion in H295R cells (267.7 $\pm 4.0 \mathrm{ng} / \mathrm{dL})$ (Fig. 1l). Testosterone secretion was also suppressed in human PCOS theca cells $(146.4 \pm 13.4 \mathrm{ng} / \mathrm{dL})(\mathrm{Fig} .1 \mathrm{~m})$ compared with the media control group $(214.7 \pm 11.8 \mathrm{ng} / \mathrm{dL})$. In summary, our data indicate that BMhMSC secreted factors inhibit androgen production.

\section{BM-hMSC secretome exerts an anti-inflammatory effect on H295R cells}

Chronic inflammation is a major factor affecting the ovarian microenvironment in patients with PCOS inducing higher ovarian androgen production (34-37), that involves two pro-inflammatory cytokines, interleukin-1 beta (IL-1 $\beta$ ) and tumor necrosis factor (TNF- $\alpha$ ) (38). Treatment of H295R cells with BMhMSC secretome significantly downregulated gene expression of IL-1 $\beta$ (IL 1B: $0.04 \pm 0.003$ fold) and TNFa (TNFA: $0.85 \pm 0.02$ fold) compared with the control media group (Fig. $1 \mathrm{n}, 0$ ), indicating a decreased inflammatory response after treatment.

\section{IL-10 decreases steroidogenesis-related gene expression and androgen production in H295R cells}

Based on the observed anti-inflammatory effect of the BM-hMSC secretome, we tested the effect of the anti-inflammatory cytokine, IL-10, which is known to be released by MSC $(31,39,40)$. IL-10 exerts immune-suppressive and anti-inflammatory effects in several disorders, including PCOS $(31,41)$. Recent reports highlighted a significantly lower serum level of IL-10 in women with PCOS compared with ageand BMI-matched healthy controls (42). High IL-10 levels may also increase insulin sensitivity by ameliorating the inflammatory responses to TNF- $a$ and IL-6, which contribute to insulin resistance in 
PCOS $(43,44)$. First, we explored IL-10 secretion from BM-MSCs by ELISA of conditioned media. We found a high concentration of IL-10 (164.8 pg/ml) compared with control media (1.32 pg/ml; Fig. 2a). We then examined the effect of IL-10 on steroidogenesis-related gene expression and androgen production in $\mathrm{H} 295 \mathrm{R}$ cells. As shown in Figure 2, recombinant human IL-10 treatment significantly downregulated the expression of CYP17A1 (Control: $1.03 \pm 0.01$ fold, $125 \mathrm{pg} / \mathrm{ml}: 0.91 \pm 0.01,250 \mathrm{pg} / \mathrm{ml}: 0.89 \pm 0.00$ fold, $500 \mathrm{pg} / \mathrm{ml}: 0.86 \pm 0.04$ fold) and CYP11A1 (Control: $1.00 \pm 0.03$ fold, $125 \mathrm{pg} / \mathrm{ml}: 0.84 \pm 0.02,250 \mathrm{pg} / \mathrm{ml}$ : $0.87 \pm 0.01$ fold, $500 \mathrm{pg} / \mathrm{ml}: 0.86 \pm 0.00$ fold), and DENND1A (Control: $1.00 \pm 0.02$ fold, $125 \mathrm{pg} / \mathrm{ml}: 0.87 \pm$ $0.01,250 \mathrm{pg} / \mathrm{ml}: 0.92 \pm 0.03$ fold, $500 \mathrm{pg} / \mathrm{ml}: 0.86 \pm 0.02$ fold) in H295R cells compared with untreated controls (Fig. 2b-d). Additionally, IL-10 significantly decreased testosterone (Control: $1.56 \pm 0.02 \mathrm{ng} / \mathrm{ml}$, $125 \mathrm{pg} / \mathrm{ml}: 1.52 \pm 0.01 \mathrm{ng} / \mathrm{ml}, 250 \mathrm{pg} / \mathrm{ml}: 1.42 \pm 0.06 \mathrm{ng} / \mathrm{ml}, 500 \mathrm{pg} / \mathrm{ml}: 1.32 \pm 0.10 \mathrm{ng} / \mathrm{ml}$ ) and androstenedione (Control: $1.55 \pm 0.03 \mathrm{ng} / \mathrm{ml}, 125 \mathrm{pg} / \mathrm{ml}: 1.44 \pm 0.04 \mathrm{ng} / \mathrm{ml}, 250 \mathrm{pg} / \mathrm{ml}: 1.34 \pm 0.04$ $\mathrm{ng} / \mathrm{ml}, 500 \mathrm{pg} / \mathrm{ml}: 1.38 \pm 0.10 \mathrm{ng} / \mathrm{ml}$ ) secretion from H295R cells in a dose-dependent manner compared with the control group (Fig. 2e, f). Our data suggest that IL-10 inhibits androgen production by regulating steroidogenic gene expression.

\section{IL-10 exerts an anti-inflammatory effect on H295R cells}

Next, we explored the anti-inflammatory effects of IL-10 on H295R cells by measuring expression of key pro-inflammatory cytokines, IL-6, TNF- $a$, and IL- $1 \beta$, following IL-10 treatment. All tested concentrations of IL-10 significantly downregulated IL 6 (Control: $1.00 \pm 0.08$ fold, $125 \mathrm{pg} / \mathrm{ml}: 0.73 \pm 0.03$ fold, $250 \mathrm{pg} / \mathrm{ml}$ : $0.79 \pm 0.02$ fold, $500 \mathrm{pg} / \mathrm{ml}: 0.70 \pm 0.11$ fold), TNFA (Control: $1.00 \pm 0.04$ fold, $125 \mathrm{pg} / \mathrm{ml}: 0.44 \pm 0.02$ fold, $250 \mathrm{pg} / \mathrm{ml}: 0.59 \pm 0.07$ fold, $500 \mathrm{pg} / \mathrm{ml}: 0.54 \pm 0.04$ fold), and $I L 1 B$ (Control: $1.00 \pm 0.04$ fold, 125 $\mathrm{pg} / \mathrm{ml}: 0.84 \pm 0.02$ fold, $250 \mathrm{pg} / \mathrm{ml}: 0.60 \pm 0.08$ fold, $500 \mathrm{pg} / \mathrm{ml}: 0.76 \pm 0.1$ fold) gene expression compared with untreated controls (Fig. $2 \mathrm{~g}-\mathrm{i}$ ). Together, these data suggest that IL-10 is a key mediator of the effect of the BM-hMSC secretome on in vitro human cell PCOS models.

\section{BM-hMSC reverse the metabolic phenotypes in an LTZ-induced PCOS mouse model}

Next, we evaluated the potential therapeutic effects of BM-hMSC in vivo by injecting BM-hMSC into the ovaries of the well-established LTZ-induced PCOS mouse model (19). Five weeks after LTZ implantation, the mice in the PCOS group were significantly heavier ( $21.1 \pm 0.25$ grams) compared with age-matched control mice (19.3 \pm 0.60 grams) that had received placebo pellets (Fig. 3a, b). Since PCOS women have insulin resistance and impaired glucose tolerance (45), we also performed a glucose tolerance test (GTT) and measured energy expenditure in PCOS mice before (5 weeks after LTZ or placebo) and 2 weeks after BM-hMSC engraftment (7 weeks after LTZ or placebo). Interestingly, PCOS mice treated with BM-hMSC exhibited a normal glucose tolerance profile compared with untreated PCOS mice (Fig. 3c-e). Moreover, we found that the untreated PCOS group had lower energy expenditure, based on a significant difference in thermogenesis, compared with PCOS mice treated with BM-hMSC (Fig. 3f-i).

The increase in thermogenesis in BM-hMSC-treated PCOS mice encouraged us to further evaluate fat metabolism in treated versus control PCOS mice. A previous study revealed the role of brown fat cells in the regulation of total energy expenditure (46). A process called "browning," which refers to the transition 
of white fat into brown fat, is associated with upregulation of UCP-1 (47). Therefore, we stained white fat tissues collected from BM-hMSC-treated and untreated PCOS mice with UCP-1 and found greater proportions of brown-like fat cells, suggesting increased browning of white fat, in the BM-hMSC-treated group (Fig. 3j). At the molecular level, the browning process is regulated by several genes that control multiple aspects of mitochondrial activity, such as Pgc-1a, Cidea, and Prdm-16 (48). qPCR confirmed our UCP-1 immunohistochemistry results and showed significant upregulation of Ucp 1 (21.00 \pm 0.67 fold), Pgc1a (2.61 \pm 0.08 fold), Cidea (3.78 \pm 0.31 fold), and Prdm16 (5.15 \pm 0.19 fold) gene expression in white fat collected from the BM-hMSC-treated PCOS mice compared with the untreated PCOS mice (Fig. 3k-n).

We also explored marker expression levels in brown fat tissue, and found that BM-hMSC treatment increases brown fat-related marker expression even in brown fat tissue (Fig S4). These results suggest that BM-hMSC can regulate adipose tissue metabolism by ameliorating inflammation and promoting brown fat formation.

\section{BM-hMSC normalize the adipokine profile in adipose tissue in an LTZ-induced PCOS mouse model}

Weight gain associated with LTZ-induced PCOS is partially due to white fat expansion (19). The expansion of gonadal fat in our LTZ-induced PCOS mice was marked by characteristic morphologic enlargement of fat cells detected by H\&E staining (Fig S5a). Remarkably, the average size of adipocytes in the BM-hMSC-treated PCOS mice was significantly smaller than that in the untreated PCOS mice (Fig $\mathrm{S} 5 \mathrm{~b})$, approaching the normal size range of adipocytes.

White fat adipocyte expansion is usually associated with an increase in leptin that correlates inversely with adiponectin levels (49). Studies have shown that adiponectin is a pivotal adipokine that can reverse PCOS metabolism (50), acting as a humoral factor that regulates fat homeostasis by establishing crosstalk between white and brown fat cells (51). To explore such cross-talk in our PCOS mouse model, we measured gene expression of leptin and adiponectin in brown adipose tissue as well as white gonadal fat using qPCR. Treatment with BM-hMSC upregulated adiponectin and downregulated leptin expression, thus normalizing the ratio of leptin to adiponectin in brown fat tissue compared with the untreated group (Fig S5c-e). Similar findings were observed in the white gonadal fat (Fig S5f-h), highlighting the ability of BM-hMSC to normalize fat metabolism in our PCOS mouse model.

\section{Serum hormone analysis}

To assess the endocrine status following BM-hMSC engraftment, total serum hormone levels in BMhMSC-treated and untreated PCOS animals were measured. Serum T levels were significantly higher in the untreated PCOS group versus healthy controls, with no significant difference in the BM-hMSC-treated group ( $p=0.797)$. Furthermore, there were no changes in serum estrogen levels among the three groups. However, LH was significantly lower in the PCOS group than healthy controls, and LH levels decreased after BM-hMSC engraftment in PCOS mice. In addition, FSH levels were lower in the PCOS group compared with healthy controls and increased after BM-hMSC treatment, though the change was not statistically significant (Fig S6a-d). 


\section{BM-hMSC treatment reverses endometrial abnormalities in an LTZ-induced PCOS mouse model}

PCOS imparts abnormalities in endometrial tissue, such as the thickening of endometrium epithelial cells and aberration of steroid receptor gene expression (52-54). Consequently, we analyzed endometrial tissue in BM-hMSC-treated versus untreated PCOS mice. The endometrial tissue of the PCOS group showed abnormal thickness (Fig S7a) and the AIB1 gene, known to be elevated in the PCOS endometrium (54), showed significant alterations in the PCOS group endometrium. These abnormalities were reversed in the BM-hMSC-treated PCOS group (Fig S7b). Similarly, steroid receptor genes AR and ER 3 trended higher in the PCOS group and this was reversed after BM-hMSC treatment (Fig S7c, d).

Interestingly, the proliferation marker Ki-67 was significantly upregulated in BM-hMSC-treated PCOS mice compared with the untreated PCOS group (Fig S7e). Additionally, several inflammatory regulator genes such as IL6, IL16, CCL2, and TNF-a were higher in the PCOS group endometrium compared with normal control endometrium, and these changes were significantly reversed after BM-hMSC treatment (Fig S7f-i). These results suggest that intra-ovarian injection of BM-hMSC reversed various alterations in PCOS endometrium, at least partially, by normalizing steroid hormone receptors and inflammatory cytokine gene expression. These changes likely improved the quality of endometrium and contributed to the improved reproductive outcomes in the PCOS mice after BM-hMSC treatment.

\section{BM-hMSC restore fertility in an LTZ-induced PCOS mouse model}

To explore the effect of BM-hMSC treatment on reproductive function, we first analyzed ovarian morphology in BM-hMSC-treated versus untreated PCOS mice. Ovaries from untreated PCOS mice displayed typical PCOS characteristics, including lack of corpora lutea and antral follicles compared with untreated normal control mice (Fig. 4a). After intra-ovarian engraftment of BM-hMSC in both ovaries of PCOS mice, normal ovarian morphology was partially restored, including the reappearance of corpora lutea and antral follicles, as well as well-ordered stroma that was morphologically similar to that of the normal control group. These morphological changes suggest that BM-hMSC engraftment improved the pathological changes in PCOS ovaries and may potentially restore ovulation in PCOS mice (Fig. 4a).

Next, we performed a breeding experiment to test BM-hMSC's treatment capacity to restore fertility in our PCOS mouse model. We found that healthy control mice had a higher rate of fertility $(80 \%)$ than the subfertile PCOS group (10\%). Interestingly, the pregnancy rate in BM-hMSC-treated PCOS mice was restored to a rate equal to that of the control group (Fig. $4 \mathrm{~b}$ ).

We also counted the number of delivered pups in all experimental groups. As shown in Figure $4 \mathrm{~d}-\mathrm{g}$, we found that most PCOS mice were infertile. The number of pups delivered in the BM-hMSC-treated PCOS group was equivalent to the number delivered in the control group. Moreover, the average number of pups delivered per mouse in the BM-hMSC-treated PCOS group (5.5 \pm 1.1$)$ was significantly higher than that in the untreated PCOS group $(0.8 \pm 1.7 ;$ Fig. $4 \mathrm{~g})$. We also found no significant differences in the average body weight of the delivered pups between the control group and BM-hMSC-treated PCOS group at 0, 5, and 10 postnatal days (Fig. 4h). Notably, we did not observe any apparent morphological abnormalities 
in any pups during the study period. We further tested the effect of injecting the BM-hMSC secretome in our PCOS mouse model (Fig S8). Fertility of PCOS mice was restored in secretome-treated animals. These results suggest that either BM-hMSC or its secretome can restore impaired fertility in an LTZinduced PCOS mouse model with no detectable abnormalities in the delivered newborns.

\section{BM-hMSC restore normal ovarian gene expression in an LTZ-induced PCOS mouse model}

PCOS abnormalities include enhanced androgen production and altered ovarian angiogenesis (55). We next examined the effect of BM-hMSC treatment on these abnormalities in our PCOS mice in vivo, to validate our in vitro data on the secretome effects on ovarian steroidogenic gene and inflammation marker expression. Mouse ovarian tissues from BM-hMSC-treated and untreated animals were analyzed for RNA and protein levels of steroidogenesis and angiogenesis markers. Cyp17a1 gene expression was significantly elevated in PCOS ovaries (13.73 \pm 5.78 fold), which was significantly reversed after BMhMSC treatment (1.22 \pm 0.20 fold; Fig. 5a). Cyp19a 1 ( $0.14 \pm 0.02$ fold) and $F s h r(0.03 \pm 0.01$ fold) gene expression were lower in PCOS group ovaries, consistent with the prior characterization of the LTZinduced PCOS mouse model (19); levels of both genes significantly increased after BM-hMSC treatment (Cyp19a 1: $0.93 \pm 0.11$ fold, Fshr. $0.80 \pm 0.09$ fold; Fig. 5b, c). Previous studies reported an abnormal increase in ovarian angiogenesis in PCOS $(55,56)$; thus, we measured gene expression of angiogenesis marker Vegfa in untreated and BM-hMSC-treated PCOS mice. Gene expression of Vegfa was elevated in the PCOS group (7.50 \pm 3.69 fold) and decreased after BM-hMSC treatment ( $0.48 \pm 0.29$ fold; Fig. $5 d)$. Immunoblot analysis supported these results, where CYP17A1 was higher in the PCOS group $(2.21 \pm 0.14$

fold) and significantly decreased after BM-hMSC treatment (1.37 \pm 0.12 fold; Fig. 5e, f). Moreover, VEGF-A protein expression was elevated in PCOS mice (1.28 \pm 0.15 fold) and decreased after BM-hMSC treatment (1.08 \pm 0.38 fold), although the change was not statistically significant (Fig. 5e, g). Taken together, our in vivo results suggest that $\mathrm{BM}-\mathrm{hMSC}$ treatment can inhibit androgen synthesis and angiogenesis consistent with the effect of the BM-hMSC secretome on H295R cells.

\section{BM-hMSC secretome improves metabolic and reproductive phenotypes in LTZ-induced PCOS mice}

Our in vitro and in vivo data suggest that the favorable effects of BM-hMSC engraftment likely occur in a paracrine fashion via secreted humoral factors in the BM-hMSC secretome. To explore the paracrine effect of BM-hMSC in the LTZ-induced PCOS mouse model, we delivered the BM-hMSC secretome by direct intra-ovarian injection into the ovaries of mice, and various metabolic and reproductive parameters were assessed. Analysis of white fat demonstrated a significant reduction in the size of fat cells in the secretome-treated PCOS group compared with the untreated PCOS group (Fig S8a), and the expression of UCP1 in brown fat tissue was also significantly higher in the secretome-treated PCOS group compared with untreated PCOS group (Fig S8b).

Morphological comparison of ovaries among the groups of mice by H\&E staining revealed that secretome-treated PCOS ovaries had more antral follicles compared with untreated PCOS group ovaries (Fig S8c). Importantly, secretome treatment also restored fertility in PCOS mice compared with the untreated PCOS control group (Fig S8d, e). These results confirm the ability of the BM-hMSC secretome to 
reverse metabolic and reproductive abnormalities in the LTZ-induced PCOS mouse model and suggest that the positive effects of BM-hMSC are primarily mediated via paracrine action of the BM-hMSC secretome.

\section{BM-hMSC regulate inflammation via IL-10 in the LTZ-induced PCOS mouse model}

Our data showed that BM-hMSC engraftment reverses several key PCOS-related features such as insulin resistance, increased expression of androgen synthesis genes, a pro-inflammatory milieu, and abrogated fat metabolism. Notably, insulin resistance, androgen synthesis, and fat metabolism are all correlated with inflammation (57). We explored whether the effects of BM-hMSC treatment are mediated by antiinflammatory factors within its secretome, such as IL-10. We first analyzed ovarian //10 gene expression in all experimental groups. Interestingly, //10 gene expression in ovary tissue was significantly higher in BM-hMSC-treated PCOS ovaries (5.37 \pm 2.72 fold) compared with untreated PCOS ovaries $(1.19 \pm 0.46$ fold; Fig. 6a). Moreover, IL-10 receptor gene (I/10r) expression in ovary tissue was also significantly higher in the BM-hMSC-treated PCOS group ( $2.13 \pm 0.57$ fold) compared with the untreated PCOS group ( $0.65 \pm$ 0.17 fold; Fig. $6 \mathrm{~b}$ ). Several reports have demonstrated an increased pro-inflammatory milieu in fat tissues of PCOS women (58) and animal models (59). We assessed the impact of intra-ovarian delivery of BMhMSC on white gonadal fat tissue inflammatory markers using qPCR. BM-hMSC treatment significantly downregulated $/ / 6$ (0.39 \pm 0.04 fold), $/ / 1 b$ (1.0 \pm 0.41 fold), $C c / 2$ (0.43 \pm 0.02 fold), and Cd11c (0.45 \pm 0.05 fold) expression in the fat tissue of BM-hMSC-treated PCOS mice versus that of untreated PCOS mice (Fig. 6g-j). Several inflammatory regulators, such as IL-10, IFN- $y$, and TIMP-2, have been found to be lower in PCOS patients compared with healthy women (42,60-62). We tested mouse serum using an antibodybased membrane assay and found that these cytokines were significantly lower in the untreated PCOS group (IL-10: $0.50 \pm 0.08$ fold, INF-y: $0.79 \pm 0.05$ fold, TIMP-2: $0.82 \pm 0.13$ fold) compared with control mice (Fig. 6c). Importantly, these cytokines were significantly increased in PCOS mice after BM-hMSC treatment (IL-10: $1.20 \pm 0.09$ fold, INF-Y: $1.27 \pm 0.11$ fold, TIMP-2: $1.62 \pm 0.22$ fold; Fig. $6 d-f$ ). These results suggest that intra-ovarian injection of BM-hMSC has a systemic anti-inflammatory effect in the PCOS mouse model, likely mediated by IL-10 secretion from these cells.

Taken together, our data suggests that intra-ovarian injection of BM-hMSC reduces inflammation by increasing the expression of anti-inflammatory mediators such as IL-10 and its receptor in the ovary, and circulating IL-10, IFN- $\gamma$, and TIMP-2 in serum, while decreasing pro-inflammatory mediators such as IL-6, $\mathrm{IL}-1 \beta, \mathrm{CCL} 2$, and CD11c gene expression in periovarian adipose tissue.

\section{Discussion}

In this study, we report a significant inhibitory effect of the BM-hMSC secretome on steroidogenesis gene expression, inflammation, and androgen production in H295R cells, as well as in primary cultures of theca cells from women with PCOS. Additionally, our in vivo experimental data showed that intra-ovarian engraftment of BM-hMSC is capable of correcting several PCOS-related metabolic abnormalities in a mouse model of PCOS. While this LTZ-induced PCOS mouse model is infertile (19), we demonstrated that 
BM-hMSC treatment was able to restore fertility and treated mice delivered healthy pups. Interestingly, similar improvements in metabolic and reproductive endpoints were achieved with injection of BM-hMSC secretome, suggesting that most, if not all, of BM-hMSC effects in this model are paracrine in nature.

Chronic inflammation plays an important role in PCOS pathogenesis (32). BM-hMSC engraftment significantly reduced several inflammatory markers in PCOS mouse ovaries. Reports have demonstrated a positive feedback loop between inflammation and androgen production $(11,12,32)$, suggesting that androgen synthesis and inflammation could be reciprocally self-propagated. Up-regulation of CYP17A1 gene expression through oxidative stress, which is a known stimulator of inflammation $(63,64)$, also demonstrates a positive feedback loop in PCOS. Surprisingly, while there was significant suppression of androgen production in vitro after BM-hMSC secretome treatment, we did not see a difference in serum testosterone levels between the untreated PCOS and BM-hMSC-treated PCOS groups. This could be attributed to the episodic nature of steroid hormone secretion. Furthermore, our findings may highlight a limitation of the chemically (LTZ)-induced PCOS model, which primarily relies on the induction of higher testosterone accumulation via marked supraphysiological inhibition of its aromatization (19). Key ovarian steroidogenic genes as Cyp17a1 were upregulated in the PCOS group, and significantly suppressed by BM-hMSC treatment. The effect of engrafted BM-hMSC on ovarian cells could occur via cell-to-cell contact or paracrine effects through secreted humoral factors.

IL-10 is an important immune-suppressive and anti-inflammatory cytokine that is key to several human disorders, including PCOS. Recent reports showed significantly lower serum levels of IL-10 in PCOS women compared with age- and BMI-matched healthy controls (42). BM-hMSC secrete physiologically relevant quantities of IL-10 $(31,39,40)$, which we confirmed in the BM-hMSC used in this work (Fig. 2a). We showed that IL-10 treatment significantly downregulates steroidogenesis and inflammatory gene expression as well as suppresses androgen production by H295R cells (Fig. 2f). In vivo, BM-hMSC treatment significantly increased IL-10 expression in ovarian tissue and its serum concentration in PCOS mice. These results suggest that BM-hMSC can ameliorate PCOS-induced inflammation through IL-10 secretion, and IL-10-overexpressing BM-hMSC might be a novel and robust therapeutic approach for PCOS treatment (Fig. 6k).

Recently, two reports have described the utility of tail-vein injected MSCs to reverse some PCOS immunephenotypes $(65,66)$. In these studies, MSCs inhibited T cell proliferation, decreased inflammation in vitro and in vivo, and enhanced ovarian function in a PCOS animal model. However, these studies lacked translational fertility, reproductive, and metabolic outcomes data. Moreover, many reports have described that, after systemic infusion, stem cells are trapped in the lungs with limited in vivo persistence (67-69). In contrast, local engraftment of hMSCs directly into the target organ, as we describe here, can initiate the reparative process in a more robust manner for cell homing and effective tissue repair (70). Additional research is needed to evaluate the utility of intra-ovarian engraftment of BM-hMSC as a potentially promising approach for the treatment of PCOS-associated infertility in women.

\section{Conclusions}


Polycystic ovary syndrome (PCOS) is the most common disease in women. Many PCOS patient typically shows excessive inflammation and infertility. In this study, we present a stem cell-based therapy to restore fertility in PCOS condition. We report that BM-hMSC secretome inhibit steroidogenesis, inflammation, and androgen production in both H295R cells and primary cultured theca cell. We also report the therapeutic efficacy of mesenchymal stem cells (BM-hMSC) in PCOS mouse models. Our study shows that BM-hMSC can treat PCOS-related characteristics, including infertility. This approach may represent a novel therapeutic option for women with PCOS.

\section{List Of Abbreviations}

BM-hMSC: Bone marrow derived human mesenchymal stem cell

PCOS: Polycystic ovary syndrome

LTZ: Letrozole

IHC: Immunohistochemistry

qRT-PCR: Quantitative real-time polymerase chain reaction

IL-1 $\beta$ : Interleukin-1 beta

IL-10: Interleukin-10

TNF-a: Tumor necrosis factor

MSCGM: Mesenchymal stem cell growth medium

FBS: Fetal bovine serum

PBS: Phosphate-buffered saline

UIC ACC: University of Illinois at Chicago Animal Care Committee

CLAMS: Comprehensive Lab Animal Monitoring System

$\mathrm{VO}_{2}$ : Oxygen consumption rate

$\mathrm{VCO}_{2}$ : Carbon dioxide release

RER: Respiratory exchange ratio

T: Testosterone

E2: Estradiol 
LH: Luteinizing hormone

FSH: Follicle-stimulating hormone

H\&E: Hematoxylin-eosin

\section{Declarations}

\section{Ethics approval and consent to participate}

The animal experiment protocol for this study was approved by the University of Illinois at Chicago Animal Care Committee (UIC ACC). All animal experiments were performed in compliance with the University of Illinois at Chicago's policies and guidelines for use of laboratory animals.

\section{Consent for publication}

Not applicable

\section{Availability of data and materials}

Not applicable

\section{Competing interests}

The authors declare that they have no competing interests.

\section{Funding}

Supported by start-up funds from the University of Illinois at Chicago(AA) and start-up funds from University of Chicago(AA)

\section{Author contribution}

Rishi Man Chugh, Hang-soo Park, and Abdeljabar El Andaloussi were equally involved in experimental design, performing the experiments, data analysis, and writing the manuscript. Hang-soo Park, Rishi Man Chugh, Amro Elsharoud, Sahar Esfandyari, Mara Ulin, Lale Bakir, Alshimaa Aboalsoud, Prosper Igboeli, and Mohamed Ali participated in the animal experiments and tissue collection. Dalia Ashour participated in cell culture. Nahed Ismail contributed scientific ideas and Ayman Al-Hendy edited the manuscript. Jan McAllister provided the human PCOS theca cells for the study. Ayman Al-Hendy led the entire study as a corresponding author. All authors read and approved the final manuscript.

\section{Acknowledgments}


This study was financially supported by start-up funds from the University of Illinois at Chicago and University of Chicago. Special thanks to Dr. Mona Omar for technical help in pilot experiments. We also thank to Dr. Jerry Strauss and Dr. Frank González for pre-reviewing our manuscript.

\section{References}

1. Fauser BC, Tarlatzis BC, Rebar RW, Legro RS, Balen AH, Lobo R, et al. Consensus on women's health aspects of polycystic ovary syndrome (PCOS): the Amsterdam ESHRE/ASRM-Sponsored 3rd PCOS Consensus Workshop Group. Fertil Steril. 2012 Jan;97(1):28-38 e25.

2. March WA, Moore VM, Willson KJ, Phillips DI, Norman RJ, Davies MJ. The prevalence of polycystic ovary syndrome in a community sample assessed under contrasting diagnostic criteria. Hum Reprod. 2010 Feb;25(2):544-51.

3. Helena CV, Cristancho-Gordo R, Gonzalez-Iglesias AE, Tabak J, Bertram R, Freeman ME. Systemic oxytocin induces a prolactin secretory rhythm via the pelvic nerve in ovariectomized rats. Am J Physiol Regul Integr Comp Physiol. 2011 Sep;301(3):R676-81.

4. Muscogiuri G, Colao A, Orio F. Insulin-Mediated Diseases: Adrenal Mass and Polycystic Ovary Syndrome. Trends Endocrinol Metab. 2015 Oct;26(10):512-4.

5. Dumesic DA, Lobo RA. Cancer risk and PCOS. Steroids. 2013 Aug;78(8):782-5.

6. Lindholm A, Andersson L, Eliasson M, Bixo M, Sundstrom-Poromaa I. Prevalence of symptoms associated with polycystic ovary syndrome. Int J Gynaecol Obstet. 2008 Jul;102(1):39-43.

7. Scicchitano P, Dentamaro I, Carbonara R, Bulzis G, Dachille A, Caputo P, et al. Cardiovascular Risk in Women With PCOS. Int J Endocrinol Metab. 2012 Fall;10(4):611-8.

8. Corbould A. Effects of androgens on insulin action in women: is androgen excess a component of female metabolic syndrome? Diabetes Metab Res Rev. 2008 Oct;24(7):520-32.

9. de Luca C, Olefsky JM. Inflammation and insulin resistance. FEBS Lett. 2008 Jan 9;582(1):97-105.

10. Fox CW, Zhang L, Sohni A, Doblado M, Wilkinson MF, Chang RJ, et al. Inflammatory Stimuli Trigger Increased Androgen Production and Shifts in Gene Expression in Theca-Interstitial Cells. Endocrinology. 2019 Oct 10.

11. Lang Q, Yidong X, Xueguang Z, Sixian W, Wenming X, Tao Z. ETA-mediated anti-TNF-alpha therapy ameliorates the phenotype of PCOS model induced by letrozole. PLoS One. 2019;14(6):e0217495.

12. Gonzalez F, Sia CL, Bearson DM, Blair HE. Hyperandrogenism induces a proinflammatory TNFalpha response to glucose ingestion in a receptor-dependent fashion. J Clin Endocrinol Metab. 2014 May;99(5):E848-54.

13. Nehir Aytan A, Bastu E, Demiral I, Bulut H, Dogan M, Buyru F. Relationship between hyperandrogenism, obesity, inflammation and polycystic ovary syndrome. Gynecol Endocrinol. 2016 Sep;32(9):709-13.

14. Nourian Dehkordi A, Mirahmadi Babaheydari F, Chehelgerdi M, Raeisi Dehkordi S. Skin tissue engineering: wound healing based on stem-cell-based therapeutic strategies. Stem Cell Research \& 
Therapy. 2019 2019/03/29;10(1):111.

15. Xiao J, Yang R, Biswas S, Qin X, Zhang M, Deng W. Mesenchymal stem cells and induced pluripotent stem cells as therapies for multiple sclerosis. Int J Mol Sci. 2015;16(5):9283-302.

16. Soleymaninejadian E, Pramanik K, Samadian E. Immunomodulatory properties of mesenchymal stem cells: cytokines and factors. Am J Reprod Immunol. 2012 Jan;67(1):1-8.

17. Choi JJ, Yoo SA, Park SJ, Kang YJ, Kim WU, Oh IH, et al. Mesenchymal stem cells overexpressing interleukin-10 attenuate collagen-induced arthritis in mice. Clin Exp Immunol. 2008;153(2):269-76.

18. Esfandyari S, Chugh RM, Park HS, Hobeika E, Ulin M, Al-Hendy A. Mesenchymal Stem Cells as a Bio Organ for Treatment of Female Infertility. Cells. 2020 Oct 8;9(10).

19. Kauffman AS, Thackray VG, Ryan GE, Tolson KP, Glidewell-Kenney CA, Semaan SJ, et al. A Novel Letrozole Model Recapitulates Both the Reproductive and Metabolic Phenotypes of Polycystic Ovary Syndrome in Female Mice. Biol Reprod. 2015 Sep;93(3):69.

20. Skarra DV, Hernandez-Carretero A, Rivera AJ, Anvar AR, Thackray VG. Hyperandrogenemia Induced by Letrozole Treatment of Pubertal Female Mice Results in Hyperinsulinemia Prior to Weight Gain and Insulin Resistance. Endocrinology. 2017 Sep 1;158(9):2988-3003.

21. Hecker M, Newsted JL, Murphy MB, Higley EB, Jones PD, Wu R, et al. Human adrenocarcinoma (H295R) cells for rapid in vitro determination of effects on steroidogenesis: hormone production. Toxicol Appl Pharmacol. 2006 Nov 15;217(1):114-24.

22. McAllister JM, Han AX, Modi BP, Teves ME, Mavodza GR, Anderson ZL, et al. miRNA Profiling Reveals miRNA-130b-3p Mediates DENND1A Variant 2 Expression and Androgen Biosynthesis. Endocrinology. 2019 Aug 1;160(8):1964-81.

23. Marti N, Bouchoucha N, Sauter K-S, Flück CE. Resveratrol inhibits androgen production of human adrenocortical H295R cells by lowering CYP17 and CYP21 expression and activities. PLOS ONE. 2017;12(3):e0174224.

24. McAllister JM. Functional, long-term human theca and granulosa cell cultures from polycystic ovaries. Endocrine. 1995 Feb;3(2):143-9.

25. McAllister JM, Modi B, Miller BA, Biegler J, Bruggeman R, Legro RS, et al. Overexpression of a DENND1A isoform produces a polycystic ovary syndrome theca phenotype. Proc Natl Acad Sci U S A. 2014 Apr 15;111(15):E1519-27.

26. Nelson VL, Legro RS, Strauss JF, 3rd, McAllister JM. Augmented androgen production is a stable steroidogenic phenotype of propagated theca cells from polycystic ovaries. Mol Endocrinol. 1999 Jun;13(6):946-57.

27. Nelson VL, Qin KN, Rosenfield RL, Wood JR, Penning TM, Legro RS, et al. The biochemical basis for increased testosterone production in theca cells propagated from patients with polycystic ovary syndrome. J Clin Endocrinol Metab. 2001 Dec;86(12):5925-33.

28. Nelson-Degrave VL, Wickenheisser JK, Hendricks KL, Asano T, Fujishiro M, Legro RS, et al. Alterations in mitogen-activated protein kinase kinase and extracellular regulated kinase signaling in theca cells 
contribute to excessive androgen production in polycystic ovary syndrome. Mol Endocrinol. 2005 Feb;19(2):379-90.

29. Wickenheisser JK, Biegler JM, Nelson-Degrave VL, Legro RS, Strauss JF, 3rd, McAllister JM. Cholesterol side-chain cleavage gene expression in theca cells: augmented transcriptional regulation and mRNA stability in polycystic ovary syndrome. PLoS One. 2012;7(11):e48963.

30. Hernandez N, Mauri M, Alfayate R, Torregrosa ME, Chinchilla V. A fifty-one-year-old woman with raised testosterone concentration. Endocrinol Nutr. 2011 Jan;58(1):50-1.

31. Qu X, Liu X, Cheng K, Yang R, Zhao RC. Mesenchymal stem cells inhibit Th17 cell differentiation by IL-10 secretion. Exp Hematol. 2012 Sep;40(9):761-70.

32. Fox CW, Zhang L, Sohni A, Doblado M, Wilkinson MF, Chang RJ, et al. Inflammatory Stimuli Trigger Increased Androgen Production and Shifts in Gene Expression in Theca-Interstitial Cells. Endocrinology. 2019;160(12):2946-58.

33. Wickenheisser JK, Quinn PG, Nelson VL, Legro RS, Strauss JF, III, McAllister. JM. Differential Activity of the Cytochrome P450 17a-Hydroxylase and Steroidogenic Acute Regulatory Protein Gene Promoters in Normal and Polycystic Ovary Syndrome Theca Cells1. The Journal of Clinical Endocrinology \& Metabolism. 2000;85(6):2304-11.

34. Ilie I, Pepene C, Duncea I, Ilie R. Vascular abnormalities and low-grade chronic inflammation in women with polycystic ovary syndrome: Relationships with insulin resistance, obesity and hyperandrogenemia. 2008;3(3):257.

35. Kelly CCJ, Lyall H, Petrie JR, Gould GW, Connell JMC, Sattar N. Low Grade Chronic Inflammation in Women with Polycystic Ovarian Syndrome. The Journal of Clinical Endocrinology \& Metabolism. 2001;86(6):2453-5.

36. Spritzer PM, Lecke SB, Satler F, Morsch DM. Adipose tissue dysfunction, adipokines, and low-grade chronic inflammation in polycystic ovary syndrome. 2015;149(5):R219.

37. Repaci A, Gambineri A, Pasquali R. The role of low-grade inflammation in the polycystic ovary syndrome. Mol Cell Endocrinol. 2011 Mar 15;335(1):30-41.

38. Guo R, Zheng Y, Yang J, Zheng N. Association of TNF-alpha, IL-6 and IL-1 beta gene polymorphisms with polycystic ovary syndrome: a meta-analysis. BMC Genet. 2015;16(1):5-.

39. Kyurkchiev D, Bochev I, Ivanova-Todorova E, Mourdjeva M, Oreshkova T, Belemezova K, et al. Secretion of immunoregulatory cytokines by mesenchymal stem cells. World J Stem Cells. 2014 Nov 26;6(5):552-70.

40. Wang J, Ren H, Yuan X, Ma H, Shi X, Ding Y. Interleukin-10 secreted by mesenchymal stem cells attenuates acute liver failure through inhibiting pyroptosis. Hepatol Res. 2018 Feb;48(3):E194-E202.

41. Iyer SS, Cheng G. Role of interleukin 10 transcriptional regulation in inflammation and autoimmune disease. Crit Rev Immunol. 2012;32(1):23-63.

42. Talaat RM, Mohamed YA, Mohamad EH, Elsharkawy M, Guirgis AA. Interleukin 10 (- $1082 \mathrm{G} / \mathrm{A})$ and $(-819 \mathrm{C} / \mathrm{T})$ gene polymorphisms in Egyptian women with polycystic ovary syndrome (PCOS). Meta Gene. 2016;9:254-8. 
43. Hong E-G, Ko HJ, Cho Y-R, Kim H-J, Ma Z, Yu TY, et al. Interleukin-10 Prevents Diet-Induced Insulin Resistance by Attenuating Macrophage and Cytokine Response in Skeletal Muscle. Diabetes. 2009;58(11):2525-35.

44. Tarkun I, Cetinarslan B, Turemen E, Canturk Z, Biyikli M. Association between Circulating Tumor Necrosis Factor-Alpha, Interleukin-6, and Insulin Resistance in Normal-Weight Women with Polycystic Ovary Syndrome. Metab Syndr Relat Disord. 2006 Summer;4(2):122-8.

45. Stovall DW, Bailey AP, Pastore LM. Assessment of insulin resistance and impaired glucose tolerance in lean women with polycystic ovary syndrome. J Womens Health (Larchmt). 2011 Jan;20(1):37-43.

46. Fenzl A, Kiefer FW. Brown adipose tissue and thermogenesis. Hormone Molecular Biology and Clinical Investigation. 2014;19(1):25.

47. Harms M, Seale P. Brown and beige fat: development, function and therapeutic potential. Nat Med. 2013 Oct;19(10):1252-63.

48. Seale P, Kajimura S, Yang W, Chin S, Rohas LM, Uldry M, et al. Transcriptional control of brown fat determination by PRDM16. Cell Metab. 2007;6(1):38-54.

49. Yamauchi T, Kamon J, Waki H, Terauchi Y, Kubota N, Hara K, et al. The fat-derived hormone adiponectin reverses insulin resistance associated with both lipoatrophy and obesity. Nat Med. 2001 Aug;7(8):941-6.

50. Mirza SS, Shafique K, Shaikh AR, Khan NA, Anwar Qureshi M. Association between circulating adiponectin levels and polycystic ovarian syndrome. J Ovarian Res. 2014 Feb 7;7:18.

51. Rui L. Brown and Beige Adipose Tissues in Health and Disease. Compr Physiol. 2017;7(4):1281-306.

52. Giudice LC. Endometrium in PCOS: Implantation and predisposition to endocrine CA. Best Practice \& Research Clinical Endocrinology \& Metabolism. 2006 2006/06/01/;20(2):235-44.

53. Villavicencio A, Bacallao K, Avellaira C, Gabler F, Fuentes A, Vega M. Androgen and estrogen receptors and co-regulators levels in endometria from patients with polycystic ovarian syndrome with and without endometrial hyperplasia. Gynecologic Oncology. 2006 2006/10/01/;103(1):307-14.

54. Gregory CW, Wilson EM, Apparao KBC, Lininger RA, Meyer WR, Kowalik A, et al. Steroid Receptor Coactivator Expression throughout the Menstrual Cycle in Normal and Abnormal Endometrium. The Journal of Clinical Endocrinology \& Metabolism. 2002;87(6):2960-6.

55. Pietro MD, Pascuali N, Parborell F, Abramovich D. Ovarian angiogenesis in polycystic ovary syndrome. 2018;155(5):R199.

56. Di Pietro M, Parborell F, Irusta G, Pascuali N, Bas D, Bianchi MS, et al. Metformin Regulates Ovarian Angiogenesis and Follicular Development in a Female Polycystic Ovary Syndrome Rat Model. Endocrinology. 2015;156(4):1453-63.

57. González F, Considine RV, Abdelhadi OA, Acton AJ. Saturated Fat Ingestion Promotes Lipopolysaccharide-Mediated Inflammation and Insulin Resistance in Polycystic Ovary Syndrome. The Journal of Clinical Endocrinology \& Metabolism. 2018;104(3):934-46. 
58. Huang ZH, Manickam B, Ryvkin V, Zhou XJ, Fantuzzi G, Mazzone T, et al. PCOS is associated with increased CD11c expression and crown-like structures in adipose tissue and increased central abdominal fat depots independent of obesity. J Clin Endocrinol Metab. 2013 Jan;98(1):E17-24.

59. Hotamisligil GS, Shargill NS, Spiegelman BM. Adipose expression of tumor necrosis factor-alpha: direct role in obesity-linked insulin resistance. Science. 1993 Jan 1;259(5091):87-91.

60. Li Y, Zheng Q, Sun D, Cui X, Chen S, Bulbul A, et al. Dehydroepiandrosterone stimulates inflammation and impairs ovarian functions of polycystic ovary syndrome. J Cell Physiol. 2019 May;234(5):743547.

61. Gomes VA, Vieira CS, Jacob-Ferreira AL, Belo VA, Soares GM, Fernandes JBF, et al. Imbalanced circulating matrix metalloproteinases in polycystic ovary syndrome. Molecular and Cellular Biochemistry. 2011 2011/07/01;353(1):251-7.

62. Miller NM, Wang J, Tan Y, Dittel BN. Anti-inflammatory mechanisms of IFN-Y studied in experimental autoimmune encephalomyelitis reveal neutrophils as a potential target in multiple sclerosis. Front Neurosci. 2015;9:287-.

63. Gonzalez F, Rote NS, Minium J, Kirwan JP. Reactive oxygen species-induced oxidative stress in the development of insulin resistance and hyperandrogenism in polycystic ovary syndrome. J Clin Endocrinol Metab. 2006 Jan;91(1):336-40.

64. Mikhaylova IV, Kuulasmaa T, Jaaskelainen J, Voutilainen R. Tumor necrosis factor-alpha regulates steroidogenesis, apoptosis, and cell viability in the human adrenocortical cell line $\mathrm{NCl}-\mathrm{H} 295 \mathrm{R}$. Endocrinology. 2007 Jan;148(1):386-92.

65. Kalhori Z, Azadbakht M, Soleimani Mehranjani M, Shariatzadeh MA. Improvement of the folliculogenesis by transplantation of bone marrow mesenchymal stromal cells in mice with induced polycystic ovary syndrome. Cytotherapy. 2018 Dec;20(12):1445-58.

66. Xie Q, Xiong X, Xiao N, He K, Chen M, Peng J, et al. Mesenchymal Stem Cells Alleviate DHEA-Induced Polycystic Ovary Syndrome (PCOS) by Inhibiting Inflammation in Mice. Stem Cells Int. 2019;2019:9782373.

67. Eggenhofer E, Benseler V, Kroemer A, Popp F, Geissler E, Schlitt H, et al. Mesenchymal stem cells are short-lived and do not migrate beyond the lungs after intravenous infusion. Frontiers in Immunology. 2012 2012-September-26;3(297).

68. T. C. Saat SvdE, W. Bijman-Lachger, S. S. Korevaar, M. J. Hoogduijn, J. N. M. IJzermans, and R. W. F. de Bruin Fate and Effect of Intravenously Infused Mesenchymal Stem Cells in a Mouse Model of Hepatic Ischemia Reperfusion Injury and Resection. Stem Cells International. 2016;2016:9.

69. Xie C, Yang Z, Suo Y, Chen Q, Wei D, Weng X, et al. Systemically Infused Mesenchymal Stem Cells Show Different Homing Profiles in Healthy and Tumor Mouse Models. STEM CELLS Translational Medicine. 2017;6(4):1120-31.

70. Liu S, Zhou J, Zhang X, Liu Y, Chen J, Hu B, et al. Strategies to Optimize Adult Stem Cell Therapy for Tissue Regeneration. Int J Mol Sci. 2016;17(6):982. 
Figures
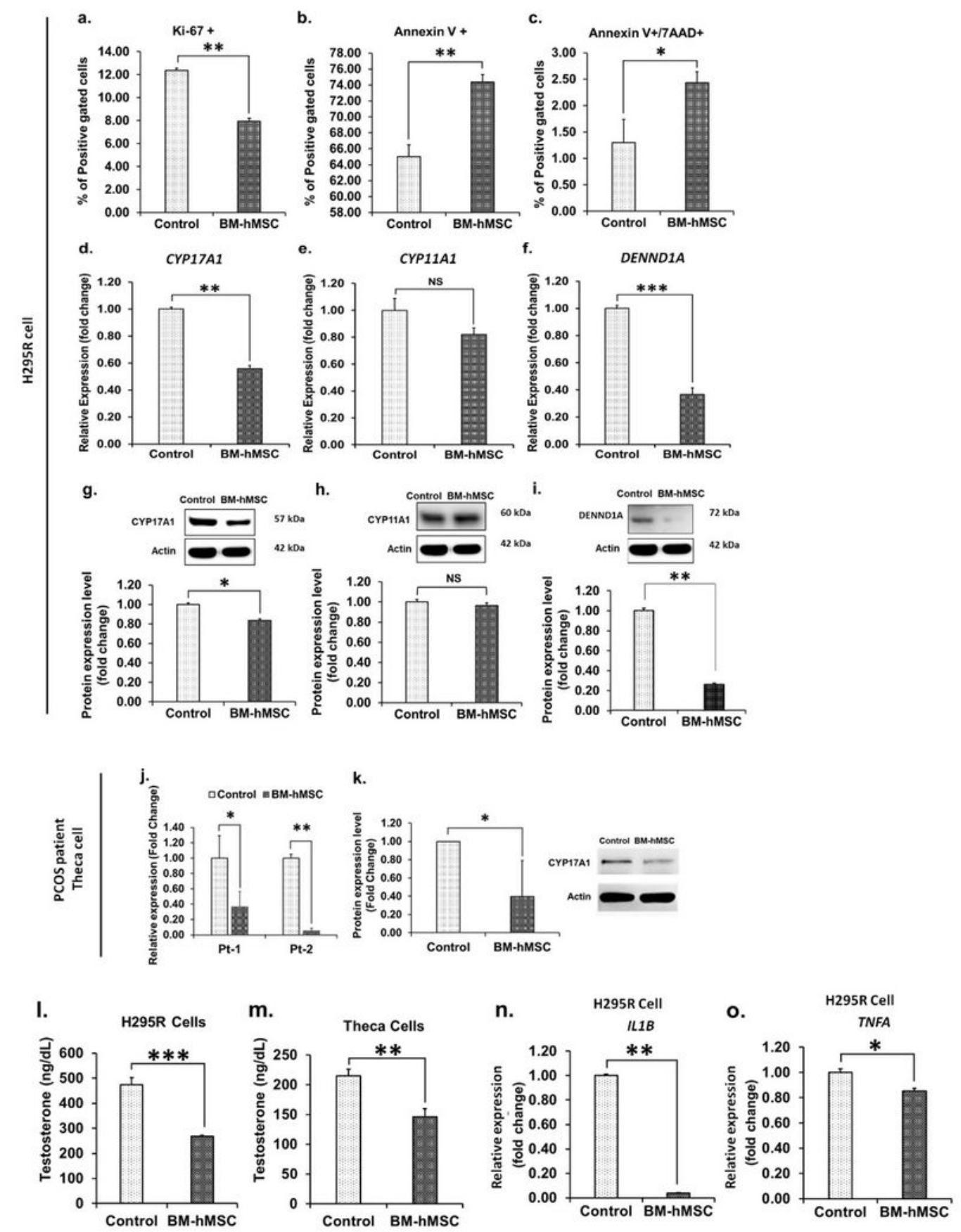

Figure 1 
Effect of BM-hMSC secretome on H295R cells and human PCOS theca cells. After 24 hours of treatment, (a) percentage of Ki67 positive cells, (b) percentage of Annexin $V$ positive cells, and (c) percentage of Annexin V+/7AAD positive cells in the BM-hMSC secretome-treated vs. control (basal media) H295R cells. (d) Relative mRNA expression of CYP17A1, (e) CYP11A1, and (f) DENND1A in BM-hMSC secretometreated vs. control H295R cells. (g) CYP17A1 protein expression, (h) CYP11A1 protein expression, and (i) DENND1A protein expression in BM-hMSC secretome-treated vs. control H295R cells. (j) Relative mRNA expression of CYP17A1 in human PCOS theca cells $(n=3)$ after BM-hMSC secretome treatment vs. control (basal media). (k) Average protein expression level of CYP17A1 in human PCOS theca cells $(n=2)$ after BM-hMSC secretome treatment vs. control. (I) Testosterone secretion by H295R cells and (m) human PCOS theca cells; BM-hMSC secretome vs. control group. (n) Relative gene expression of inflammatory marker IL1B and (o) TNFA in BM-hMSC secretome-treated vs. control basal media in H295R cells. *: $p<0.05, * \star: p<0.005, \star \star *: p<0.0005$; NS: Not significant.
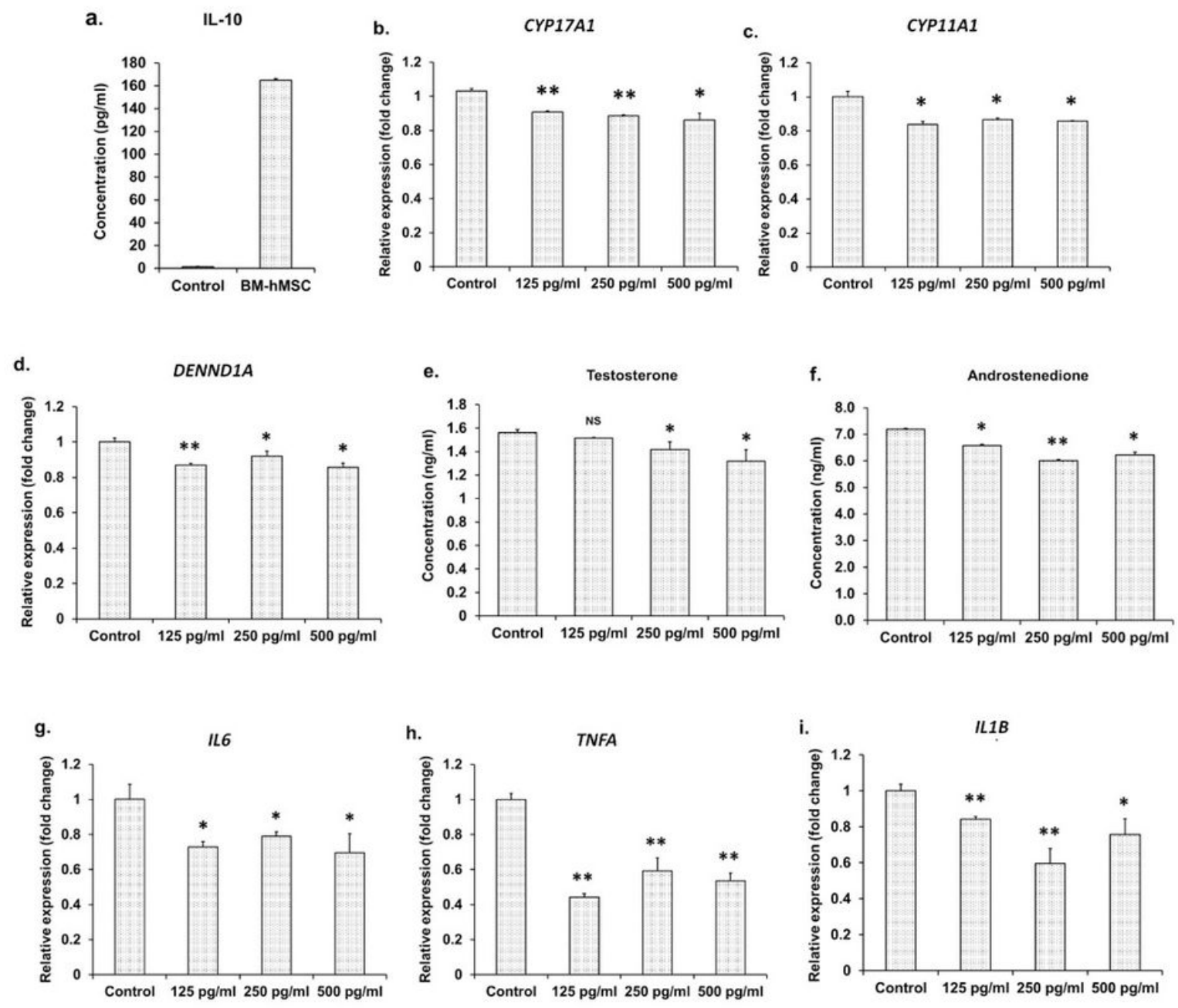
Figure 2

Effect of IL-10 on H295R cells. (a) Concentration of IL-10 secreted by BM-hMSC. (b) Relative gene expression of CYP17A1, (c) CYP11A1, and (d) DENND1A after IL-10 treatment. (e) Testosterone secretion and (f) androstenedione secretion by H295R cells after IL-10 treatment. (g) Relative gene expression of inflammatory markers IL-6 (IL6), (h) TNF-a (TNFA), and (i) IL-1 $\beta$ (IL1B) after IL-10 treatment. *: $p<0.05$, **: $\mathrm{p}<0.005$; NS: Not significant.
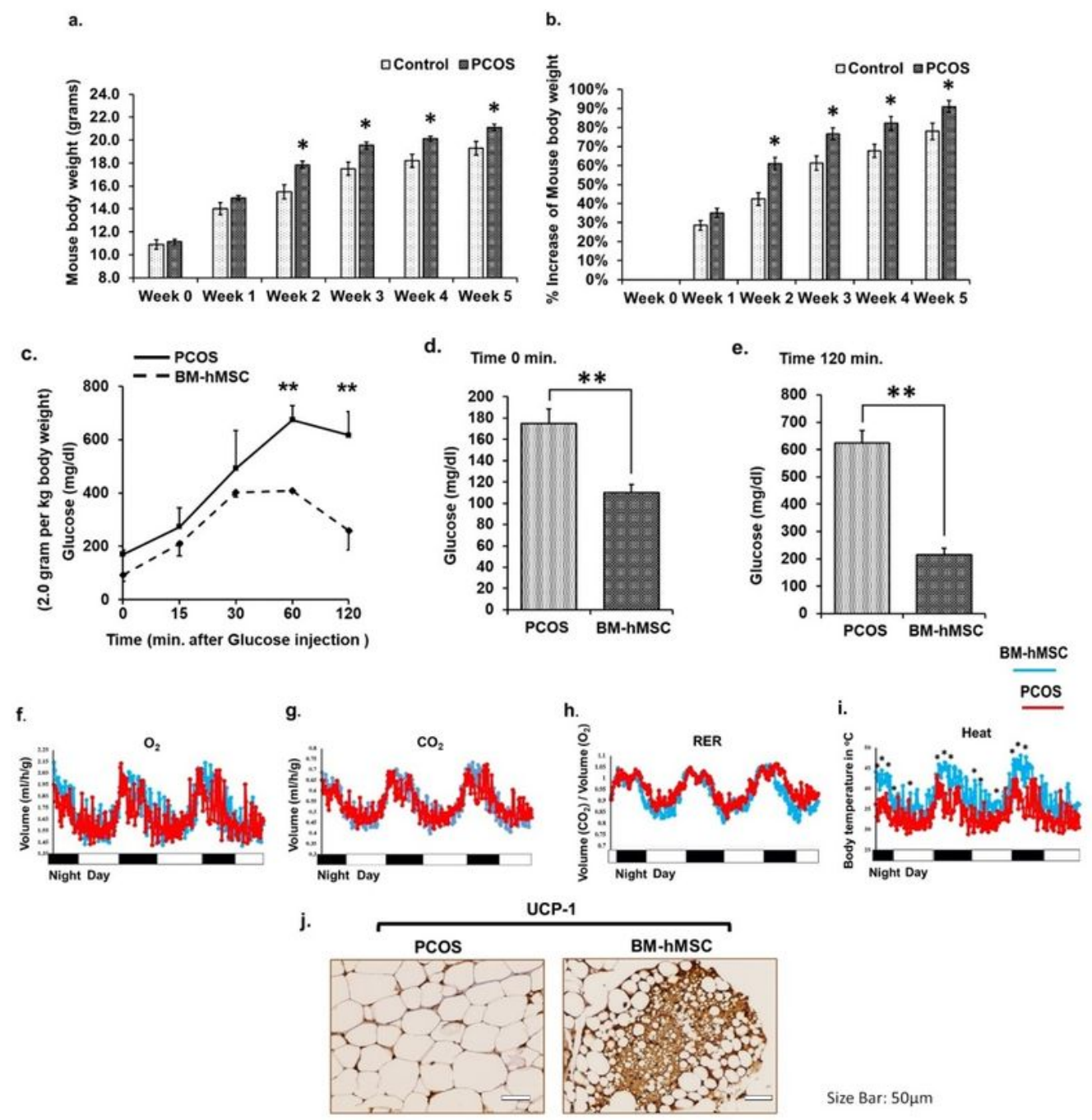

UCP-1

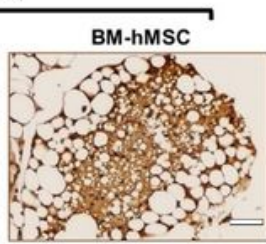

Size Bar: $50 \mu \mathrm{m}$
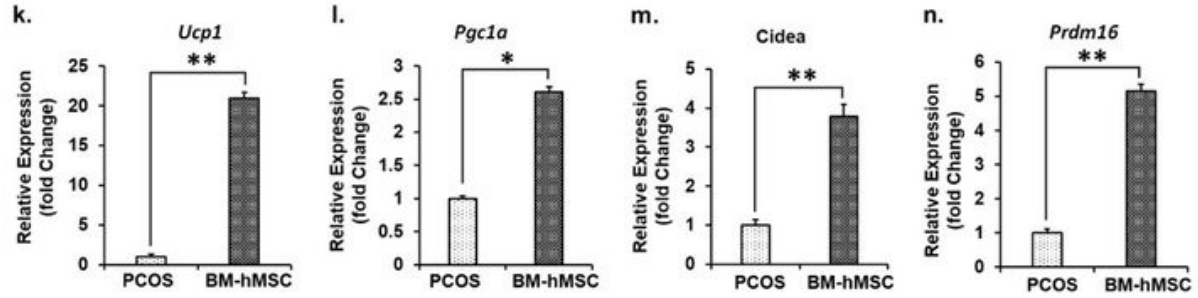


\section{Figure 3}

BM-hMSC injection into the ovary reverses metabolic phenotypes in the LTZ-induced PCOS mouse model. (a) Effect of LTZ on body weight in LTZ-treated mice (PCOS) and matched controls. Mean body weight after week 5 was significantly higher in the PCOS group compared with matched controls. (b) Percent rate of increase in body weight in control mice and PCOS mice. (c) Glucose tolerance test was performed on starved mice and mice after intraperitoneal (i.p.) glucose injection, monitored at the indicated time points for blood glucose level represented in $\mathrm{mg} / \mathrm{dL}$. (d) Blood glucose level at time $0 \mathrm{~min}$ after $16 \mathrm{~h}$ overnight fast. (e) Comparison of blood glucose level 2 hours after glucose i.p. injection. BM-hMSC enhances energy expenditure in the PCOS mouse model. (f) Oxygen (O2), (g) carbon dioxide (CO2), (h) respiratory exchange ratio (RER), and (i) heat production presented in histograms comparing energy expenditure profiles of the PCOS group and BM-hMSC-treated PCOS group. (j-n) BM-hMSC induces browning of white fat in the PCOS mouse model. (j) UCP-1 immunohistochemistry staining of white gonadal fat. Scale bar

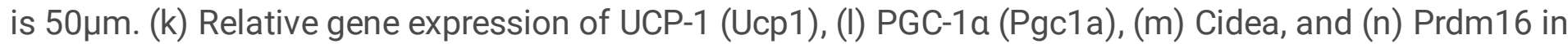
white fat from PCOS mice and BM-hMSC-treated PCOS mice. *: $p<0.05, * *: p<0.005$. 

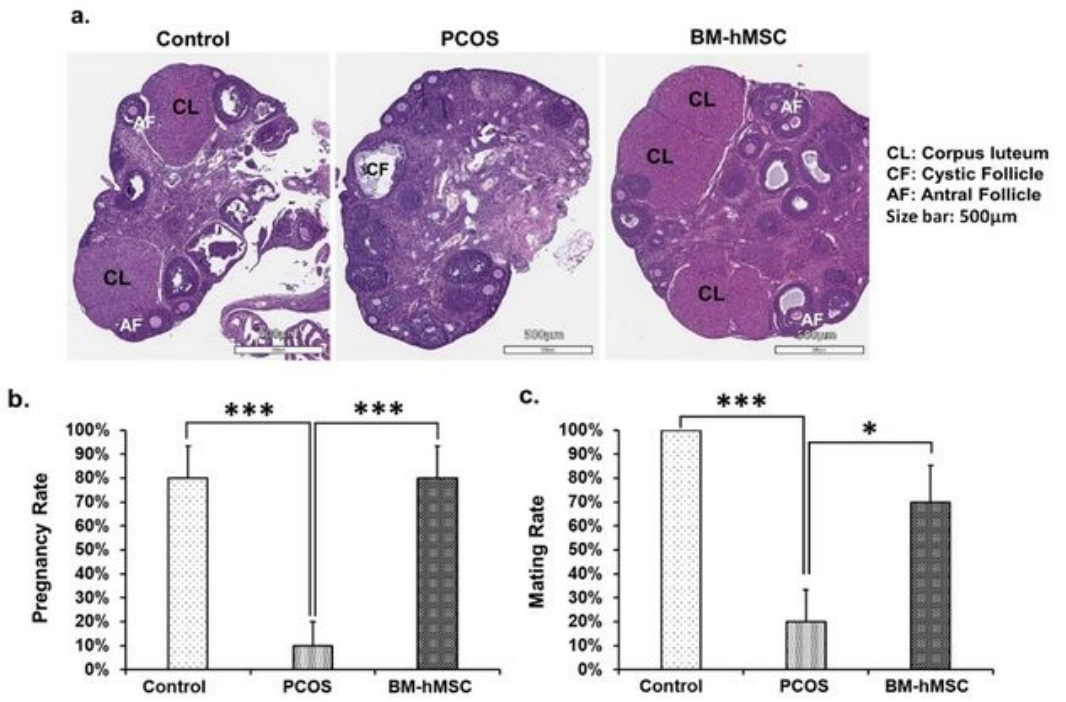

d.

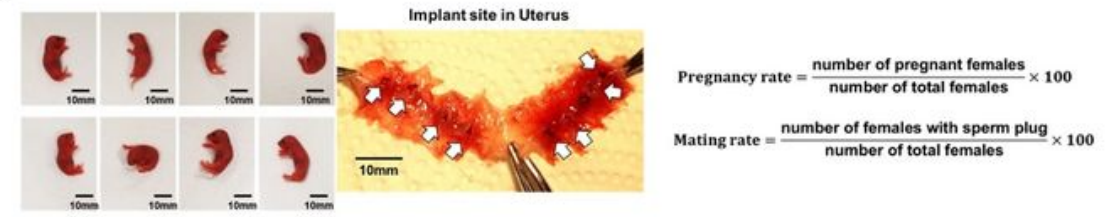

e.

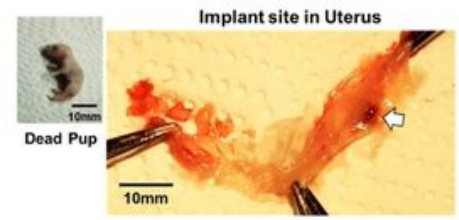

g.

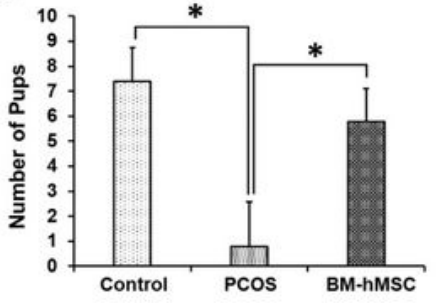

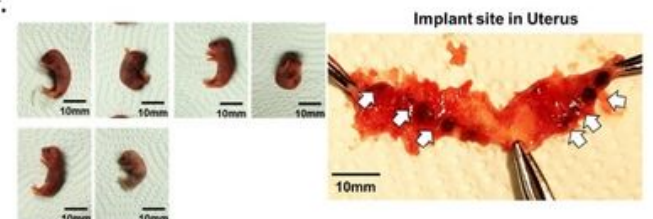

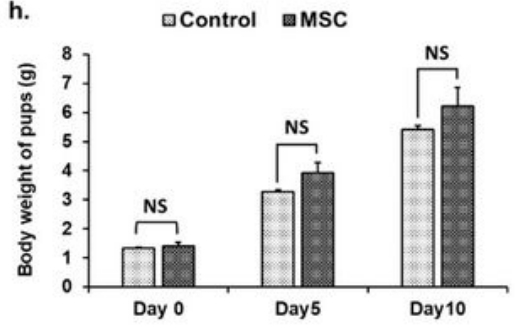

Figure 4

BM-hMSC injection into the ovary restores fertility in LTZ-induced PCOS mouse model. (a) Morphology of ovary from a normal mouse (control), LTZ-induced PCOS mouse (PCOS), and BM-hMSC-treated PCOS mouse (BM-hMSC). Scale bar is $500 \mu \mathrm{m}$. (b) Pregnancy rate of the control group (8 out of 10), PCOS group (1 out of 10), and BM-hMSC-treated group (8 out of 10). (c) The mating index (Mating rate) of the control group, PCOS group, and BM-hMSC-treated group. Morphology of pups and implantation site in the 
uterus of (d) control group, (e) PCOS group, and (f) BM-hMSC-treated group. (g) Average number of pups from the control group, PCOS group, and BM-hMSC group. (h) Average body weight of pups post-natal day 10. *: $p<0.05, * * *: p<0.0005$; NS: Not significant.

a.

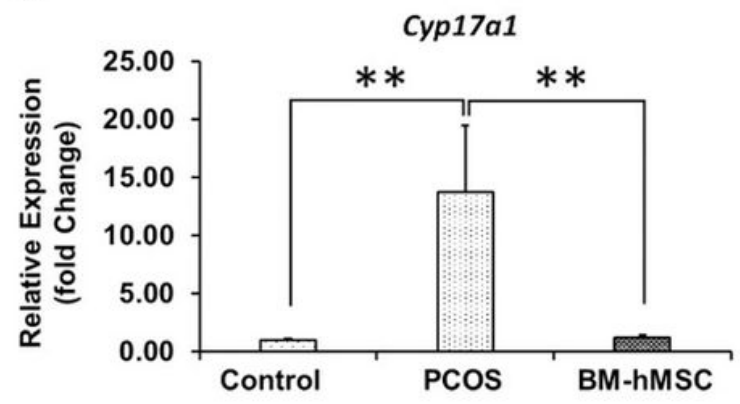

c.

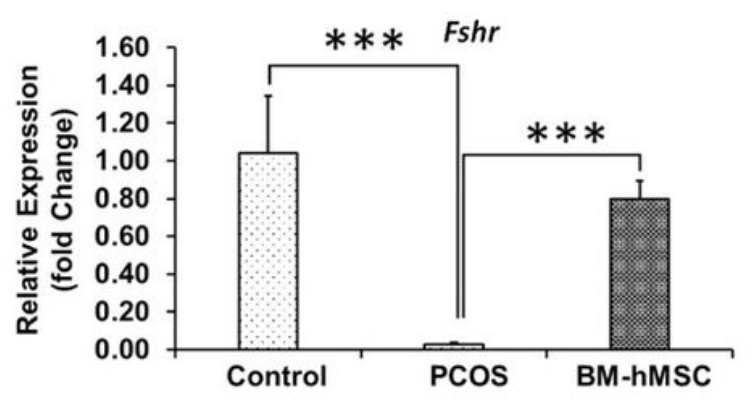

b.
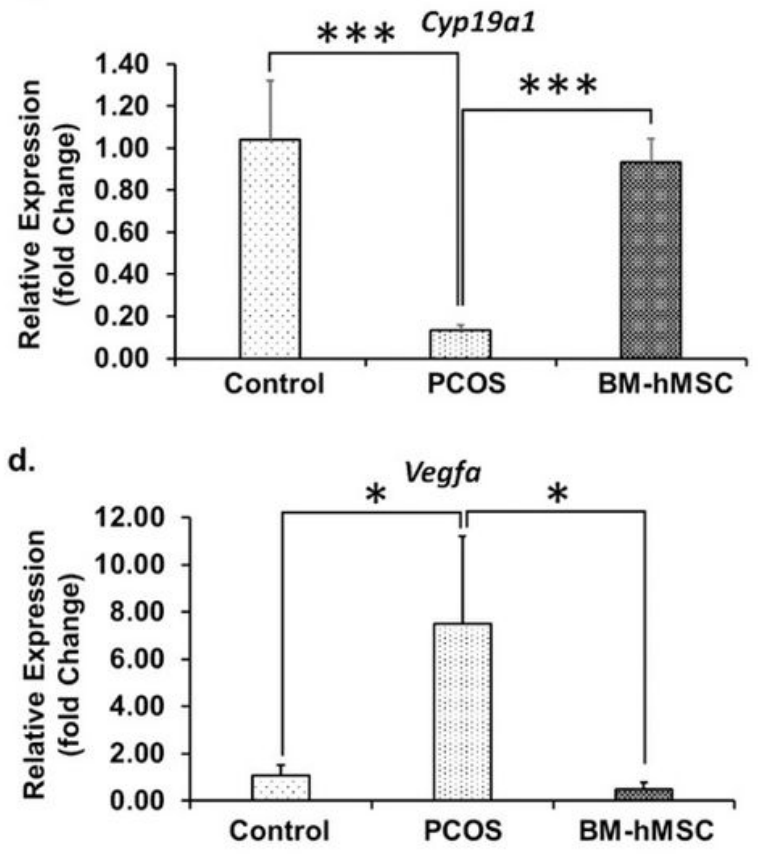

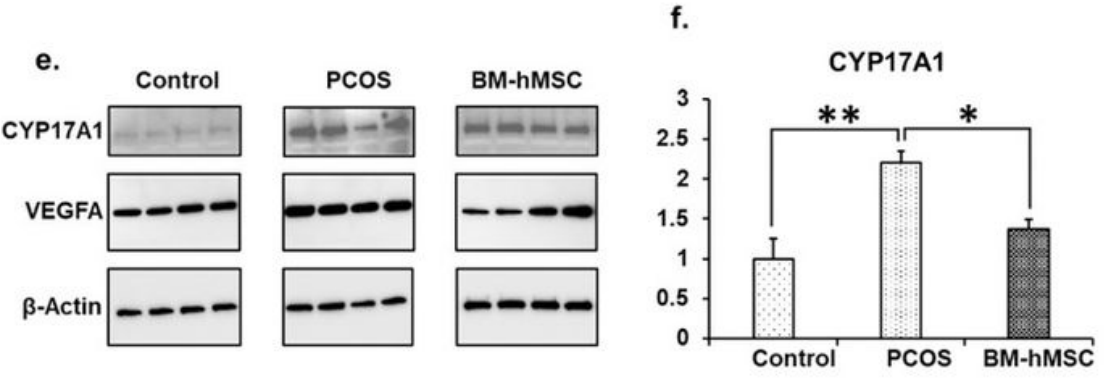

g.

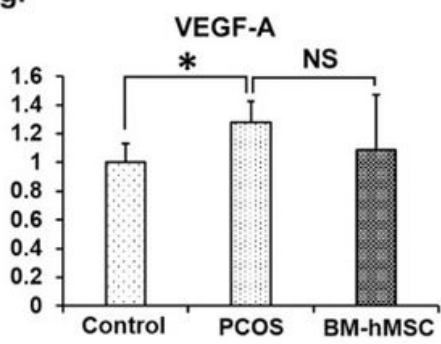

Figure 5

BM-hMSC injection into the ovary reverses altered gene expression in ovarian tissue of LTZ-induced PCOS mice. (a) Relative gene expression of Cyp17a1 (b) Cyp19a1 , (c) Fshr , and (d) Vegfa in the ovary from control, untreated PCOS, and BM-hMSC-treated PCOS mice. (e) Immunoblot of CYP17A1 and VEGFA in the ovary. (f) Quantification of CYP17A1 and (g) VEGFA in the ovary from control, PCOS, and BM-hMSCtreated PCOS mice. *: $p<0.05,{ }^{* *}: p<0.005,{ }^{\star * *}$ : $p<0.0005$; NS: Not significant. 

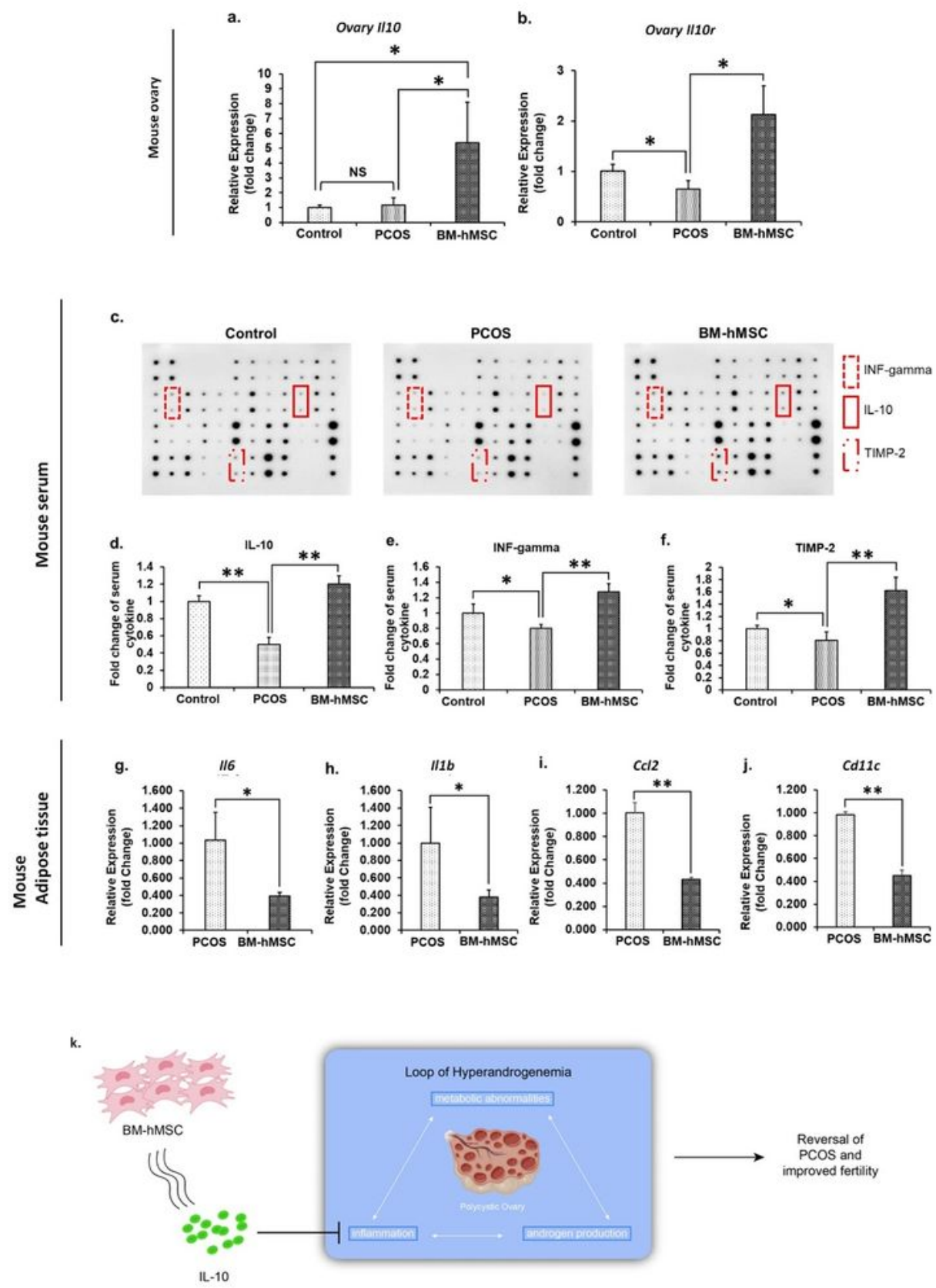

\section{Figure 6}

Effect of BM-hMSC on cytokines in the LTZ-induced PCOS mouse model. (a) Relative gene expression of IL-10 (II10) and (b) IL-10R (II10r) in the ovary from control, untreated PCOS, and BM-hMSC-treated PCOS mice. (c) Serum levels of inflammatory regulatory markers by antibody-based membrane assay. (d) Fold change of serum IL-10 (e) INF-y and (f) TIMP-2 in control, PCOS, and BM-hMSC-treated PCOS mice. (g-j) Pro-inflammation marker mRNA expression in adipose tissue. (g) Relative gene expression of IL-6 (II6) (h) 
IL-1ß (II1b), (i) CCL2 (Ccl2), and (j) CD11c(Cd11c) in untreated and BM-hMSC treated PCOS mice. (k) Schematic of the proposed model for BM-hMSC therapeutic effect in PCOS. A positive stimulation loop between inflammation, androgen production, and metabolic abnormalities could lead to PCOS. BM-hMSC alleviate the inflammation via secretion of anti-inflammatory factor IL-10, which suppresses androgen secretion by ovarian theca cells. Those effects in turn can improve the metabolic abnormalities.

Regulation of inflammation through IL-10 leads to improved fertility in PCOS. ${ }^{*}$ : $p<0.05,{ }^{*}$ : $p<0.005$; NS: Not significant.

\section{Supplementary Files}

This is a list of supplementary files associated with this preprint. Click to download.

- SupplementarydataSCRTHsParketalfinal.docx 